\title{
A Coordenação na Gramática Discursivo-Funcional
}

\author{
Erotilde Goreti Pezatti (São Paulo) e J. Lachlan Mackenzie (Coimbra)
}

\begin{abstract}
Coordination has commonly been treated as a grammatical process of connecting clauses, in which an equipollence relation may occur between the units involved. The purpose of this paper is to show how a discourse-functional theory understands coordination, relating it to the levels and layers proposed in the model of Functional Discourse Grammar (Hengeveld/Mackenzie 2008). We propose that coordination in Portuguese, as a morphosyntactic phenomenon, results from the double action of the Interpersonal and Representational Levels: the relations of addition and alternativity (expressed by $e$ and ou respectively) result not only from parallelism at the Interpersonal Level but also from operations at the Representational Level that make use of notions found in logic. The adversative relation expressed by mas, however, is shown to be identical to the additive one at the Representational Level, differing only at the Interpersonal Level, where it requires the rhetorical function Concession to be assigned to a dependent Discourse Act.
\end{abstract}

\section{Introdução}

Este estudo tem como proposta tratar do fenômeno linguístico de coordenação sob a perspectiva do funcionalismo holandês (cf. Dik 1997a, b; Hengeveld/Mackenzie 2008; Keizer 2015), com a pretensão de contribuir para o refinamento desse conceito na teoria da Gramática DiscursivoFuncional (doravante GDF), que ainda se mostra incipiente para responder algumas questões relacionadas a esse fenômeno.

Segundo Hengeveld/Mackenzie (2008: 309), a coordenação é o reflexo morfossintático de uma estratégia discursiva, que combina dois ou mais atos discursivos equipolentes (com igual estatuto comunicativo). Se os atos discursivos combinados são orações, como em (1), o processo é denominado Coordenação; se constituem sintagmas, como em (2), o processo é Listagem. ${ }^{1}$

(1) então você assa a carne só no sal e prepara o molho à parte. (BR80:ComerFalarBem).

(2) Cuba em mil novecentos e cinquenta e sete o que é que era? Reduto de americano, prostituição, contrabando de drogas e miséria. (BR87:EconomiaSociedade)

A combinação de Atos Discursivos por meio da conjunção mas ('but'), entretanto, estabelece entre eles uma relação de dependência, já que o ato introduzido por mas traz a informação

\footnotetext{
${ }^{1}$ Nos exemplos citados neste artigo, as partes mais relevantes são apresentadas em negrito. Em alguns exemplos a conjunção é adicionalmente sublinhada.
} 
comunicativamente mais relevante, como em (3), em que o primeiro ato foram educados nas escolas indonésias dá suporte argumentativo para o conteúdo comunicado no ato seguinte não perdem assim a sua identidade e o seu orgulho de ser timorense. Nesse caso, o primeiro ato (subsidiário) tem uma função retórica, denominada Concessão.

(3) eh, eu admiro-me bastante. admiro-me bastante porque... foram educados nas escolas indonésias mas não perdem assim a sua identidade e o seu orgulho de ser timorense. (TL99:IdentidadeDeUmPovo)

(4) eu não sei se é verdade ou se é mentira (CV95:AsMornas)

(5) não perdem assim a sua identidade e o seu orgulho de ser timorense (TL99:IdentidadePovo)

(6) ai menina, sempre foi assim igual mas cores diferentes, não é?, mas mesmo estilo de roupa, tudo. (BR95:MuitoIguaisDiferentes:90)

Ocorrências extraídas de um córpus do português falado, ${ }^{2}$ como (4), (5) e (6), levantam algumas questões, que se pretendem responder com este estudo.

1) a coordenação ocorre sempre entre Atos Discursivos, conforme propõem Hengeveld/Mackenzie (2008)?

2) como tratar a combinação de orações subordinadas em sentenças como (4)?

3) como tratar a combinação de constituintes suboracionais, em sentenças como (5) e (6)?

4) que tipo de processo morfossintático esses fenômenos engendram?

\section{A coordenação na Gramática Funcional ${ }^{3}$}

Segundo Dik (1997b: 189)4, principal proponente da Gramática Funcional (GF), a coordenação é uma construção que consiste em dois ou mais membros funcionalmente equivalentes, demarcados no mesmo nível da estrutura por meio de mecanismos de ligação. Isso significa que nenhum dos membros está de qualquer modo subordinado a ou dependente de qualquer outro. Eles estão todos par a par e são membros iguais da coordenação. Em outras palavras, nenhuma unidade é constituinte da outra, podendo cada qual ocorrer sozinha, mas a combinação delas constitui uma única unidade formal, conforme se representa na Figura 1, em que $C O$ significa coordenação; $M$, membro e $\&$, o mecanismo de ligação. ${ }^{5}$

\footnotetext{
2 "Português oral", desenvolvido pelo Projeto "Português Falado: Variedades Geográficas e Sociais".

${ }^{3}$ Texto reelaborado por Pezatti (2021), com base na seção $A$ Coordenação na $G(D) F$, do Capítulo I, Gramática Discursivo-Funcional e a Coordenação, que integra a obra Construções coordenadas nas variedades portuguesas: uma abordagem discursivo-funcional, organizado por Pezatti/Camacho/Hattnher (2021).

${ }^{4}$ Dik doutorou-se em 1968 com a tese sobre o fenômeno da coordenação, que foi um interesse primordial dele ao longo de sua carreira (cf. Dik 1968/1972).

${ }^{5}$ As propostas do Dik (1968/1972) foram criticadas por gerativistas como Zhang (2009), que não admitiam árvores sem binary branching.
} 


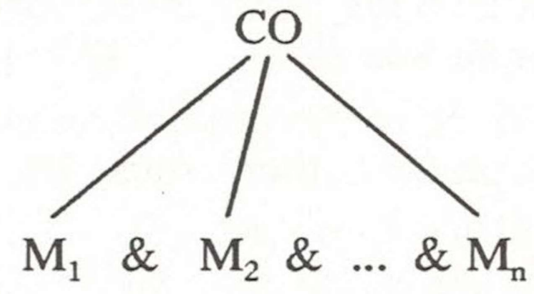

Figura 1: Coordenação (Dik 1997b: 189)

Mais importante na definição, conforme Dik (1997b: 192), é que os membros da coordenação devem ser funcionalmente equivalentes. Muitas abordagens da coordenação requerem que seus membros sejam categorialmente equivalentes. Entretanto, a estrutura categorial interna dos membros coordenados pode diferir desde que a função externa (pragmática, semântica ou sintática) seja a mesma, como em (7) e (8):

(7) Peter and several of his friends left early. (Dik 1997b: 192)

'O Pedro e alguns de seus amigos saíram cedo.'

(nome próprio e termo plural coordenados, mas ambos Agente e Sujeito da oração)

He felt quite happy and at ease in his new office. (Dik 1997b: 192)

'Ele se sentiu muito feliz e à vontade em seu novo escritório.'

(Adjp e Prepp coordenados, mas ambos funcionando como predicados)

Para Dik (1997b), equivalência funcional significa que os membros devem ter as mesmas funções pragmática, semântica e sintática. Os exemplos seguintes mostram o que acontece quando tais equivalências não ocorrem. Em (9), há a coordenação de termos com funções semânticas diferentes:

(9a) *John went to the party (Dir) and by car (Manner). (Dik 1997b: 192)

'O João foi à festa e de carro.'

(9b) *John cut the meat with a knife (Instr) and in the kitchen (Loc). (Dik 1997b: 192) 'O João cortou a carne com a faca e na cozinha.'

(9c) *John read the whole night (Dur) and a great novel (Go). (Dik 1997b: 192)

'O João leu toda noite e um grande romance.'

Em (10), a agramaticalidade da oração se deve à coordenação de termos com a mesma função semântica, mas com diferentes funções sintáticas:

(10) *John (AgSubj) by the man (Ag) kissed the girl. (Dik 1997b: 192)

'O João e pelo homem beijaram a garota.'

Podem-se coordenar, segundo Dik (1997b: 193), tanto orações independentes, que conservam sua integridade, em uma relação coordenada por justaposição, como em (11a), ou por coordenação explícita, como em (11b) e (12), quanto orações que são encaixadas num predicado, como em (13a-b).

\footnotetext{
6 Todos os exemplos em língua inglesa foram traduzidos pelos autores.
} 
(11a) John went out for a walk, Mary watched television. (Dik 1997b: 197) 'O João foi caminhar, a Maria viu televisão.'

(11b) John went out for a walk and Mary watched television. (Dik 1997b: 197) 'O João foi caminhar e a Maria viu televisão.'

(12) Finally I got a chance to give my opinion and well, to tell you the truth, I simply didn't know what to say. (Dik 1997b: 197)

'Finalmente eu tive a chance de dar a minha opinião e bem, para dizer a verdade, eu simplesmente não soube o que dizer.'

(13a) John said that he didn't feel well and that he wanted to go home. (Dik 1997b: 198) 'O João disse que não se sentia bem e que queria ir para casa.'

(13b) John asked whether Mary felt all right and whether she wanted to come along to the party. (Dik 1997b: 198)

'O João perguntou se a Maria estava bem e se queria que ele acompanhasse ela à festa.'

A coordenação de orações (independentes ou dependentes) requer em geral que os membros coordenados tenham a mesma ilocução. Em certas condições, no entanto, é possível ocorrer coordenação de orações com diferentes ilocuções, como em (14a-c).

(14a) Everybody seems to have gone and where is Mary? (Dik 1997b: 198)

'Todos parecem ter chegado e onde está a Maria?'

(14b) Everybody seems to be there but where is Mary? (Dik 1997b: 198)

'Todos parecem estar lá mas onde está a Maria?'

(14c) I don't feel like going there and why should I? (Dik 1997b: 198)

'Não tenho vontade de ir lá, e por que haveria de ir?'

A coordenação pode ainda ocorrer, de acordo com Dik (1997b: 194), entre constituintes suboracionais. Assim, ao lado da coordenação de orações, há a coordenação local de constituintes, que acontece quando o Falante, ao chegar a um certo slot na construção de uma oração, multiplica esse slot localmente, resultando numa série coordenada de itens. Nesse caso, a coordenação obedece a uma regra que multiplica constituintes suboracionais na posição em que eles ocupam na estrutura da oração. Desse modo, uma estrutura como (15) deve ser descrita, segundo o autor (Dik 1997b: 195), partindo-se do esquema de predicado do verbo deixar, multiplicando o argumento Agente em três ocorrências, conforme (16).

(15) John, Peter, and Charles left the office. (Dik 1997b: 195)

'O João, o Pedro e o Carlos deixaram o escritório.'

(16) left [V]

$$
\begin{array}{lll} 
& \left(\mathrm{x}_{1}\right)_{\mathrm{Ag}} & \left(\mathrm{x}_{2}\right)_{\mathrm{Go}} \\
\& & \left(\mathrm{x}_{1}\right)_{\mathrm{Ag}} & \\
\& & \left(\mathrm{x}_{1}\right)_{\mathrm{Ag}} &
\end{array}
$$

Essa estrutura representa (15) diretamente por meio da inserção de termos e de estratégias de expressão apropriadas. Quando a coordenação é binária, é feita somente uma cópia do item relevante; quando n-ária, $\mathrm{n}$ pode, em princípio, ter qualquer valor, embora obviamente, esse parâmetro pode ser inviável se o conjunto for muito alto. Isso pode ser representado com uma regra simples, como em (17), em que $M$ indica o membro duplicado e \& simboliza a relação coordenativa, sem prejuízo da forma particular em que será expressa.

$$
M-->M_{1} \& M_{2} \& \ldots \& M_{n}(n>1)
$$


Pode-se ativar esse esquema de regra em diferentes lugares e em vários níveis da estrutura subjacente da oração, levando a coordenações locais de diversos tipos (cf. Dik 1997b: 195), conforme exemplificam as ocorrências extraídas do córpus: (18), em que é multiplicado o argumento objeto do verbo perder; (19) em que a multiplicação ocorre na posição de modificador adjetivo do substantivo plano; e em (20) cuja multiplicação acontece na posição de modificador do Estado de Coisas.

(18) foram educados nas escolas indonésias mas não perdem assim a sua identidade e o seu orgulho de ser timorense. (TL99:IdentidadePovo)

(19) e eu entendo que se o real fosse um plano tão seguro e tranquilo, o... Estado de São Paulo, o governo de São Paulo teria tido condições de sustentar e garantir a cultura ao povo. (BR80:PlanoReal)

(20) leva-se o açúcar ao lume com um bocadinho de água muito pouco e o su [...], e o... sumo do ananás da lata, o su [...], o suco. (PT70: Bavaroise)

A multiplicação direta pode também ser usada na posição do segundo argumento de predicados como saber, persuadir, ver, resultando na coordenação de termos proposicionais e predicacionais (Dik 1997b: 201). Em (21), por exemplo, a multiplicação direta ocorre na posição do argumento exigido pelo verbo saber, resultando na coordenação de dois Conteúdos Proposicionais, se é cliente e (se) não é, coordenados. Em (22), por outro lado, há a multiplicação de duas predicações, ou seja, de Estados de coisas, fazer as minhas compras $\underline{\mathbf{e}}$ comer, que ocorrem na posição de argumento do verbo conseguir. ${ }^{7}$

(21) como é que você vai saber se é cliente ou não é? (BR80:NadaCiumenta)

(22) bem, primeiro, é que eu vivo só, não é, vivo só, e, portanto, com... os duzentos dólares que eu ganho eu consigo, pelo menos, eh, fazer as minhas compras e comer, não é, durante o, o, o mês todo. durante trinta dias. (AN97:JovemGaspar)

Dik (1997b: 199), citando Moutaouakil (1988), observa, no entanto, que orações dependentes coordenadas devem ser pragmaticamente congruentes no sentido de que devem veicular o mesmo tipo de função de Foco ou a mesma distribuição interna de Foco.

Ainda, segundo Dik (1997b: 196), não somente constituintes simples podem ser coordenados, mas também pares, triplos etc. de constituintes podem ser multiplicados localmente. Dessa forma, há coordenação simples, quando se coordenam constituintes únicos; coordenação múltipla, quando a coordenação simples se aplica a diferentes constituintes dentro da mesma construção; e coordenação simultânea, quando se aplica a dois, três ou mais itens, conforme respectivamente exemplificam (15), repetida aqui por conveniência em (23), (24) e (25).

(23) John, Peter, and Charles left the office. (Dik 1997b: 195)

'O João, o Pedro e o Carlos deixaram o escritório.'

(24) John washed the dishes and cleaned the sink. (Dik 1997b: 196)

'O João lavou a louça e limpou a pia.'

(25) John washed and Mary dried the dishes (Dik 1997b: 196)

'O João lavou e a Maria secou a louça.'

\footnotetext{
${ }^{7} \mathrm{Na}$ verdade, trata-se de uma Propriedade Configuracional, camada ainda não considerada por Dik (1997a), ou seja, ele não fazia distinção entre Estado de Coisas e Propriedade Configuracional.
} 


\section{A coordenação na GDF}

Hengeveld/Mackenzie (2008), a partir da GF (Dik 1997b), mas diferentemente dela, propõem um modelo teórico descendente, em que a construção de um enunciado padrão em situação de interação se inicia com a intenção comunicativa de uma mensagem no Componente Conceitual; ainda nessa forma pré-linguística, a mensagem passa para o Componente Gramatical, onde é formulada em unidades de conteúdo pragmático e semântico e codificada em unidades formais de natureza morfossintática e fonológica. A Figura 2 representa a arquitetura geral do modelo, conforme proposta em Hengeveld/Mackenzie (2008).

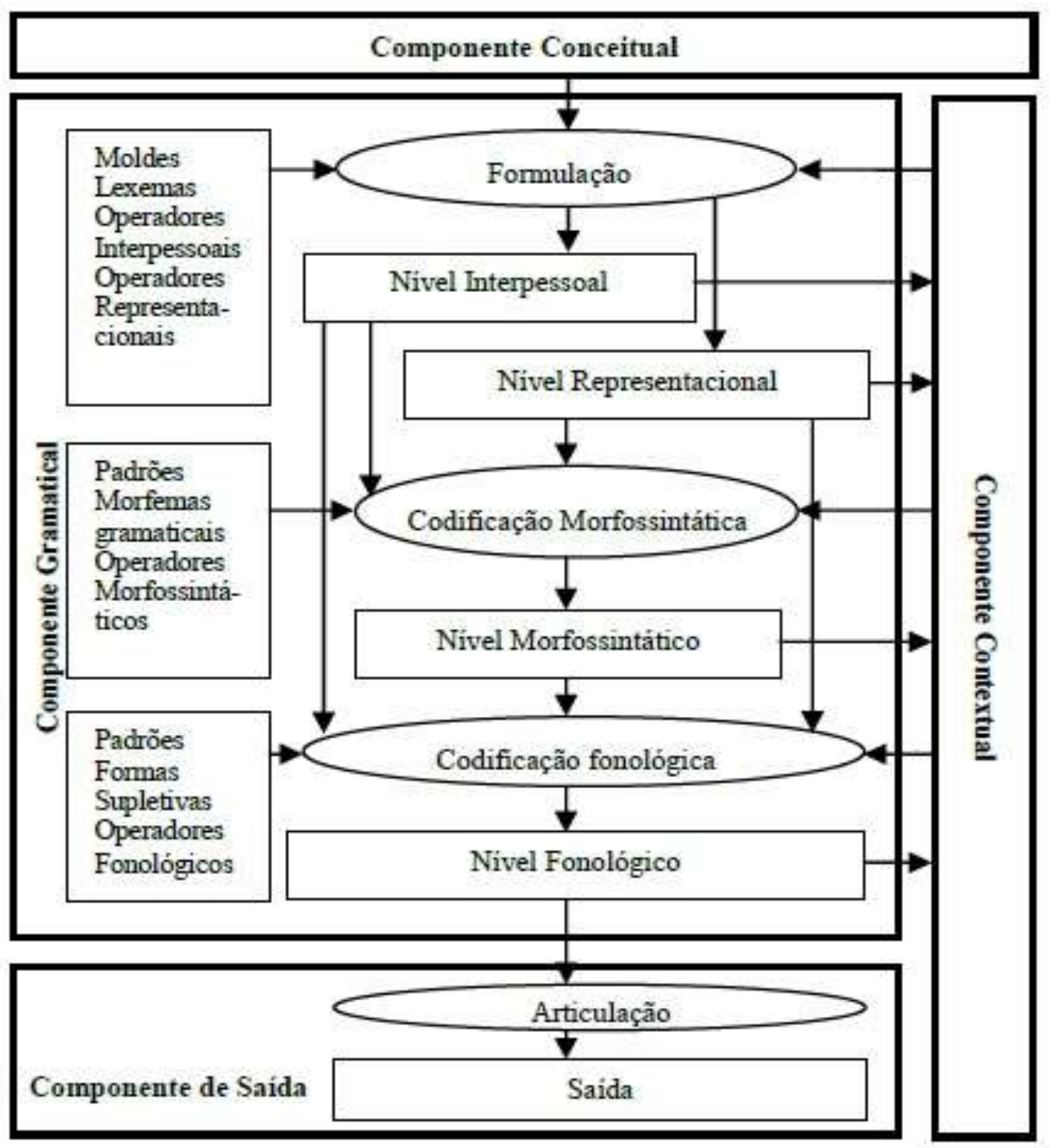

Figura 2: Layout Geral da GDF (Adaptado de Hengeveld/Mackenzie 2008: 13)

O modo descendente de organização implica que cada estágio ou componente por que passa a mensagem nesse processo constitui a entrada do estágio ou do componente seguinte. Nesse caso, o Componente Conceitual fornece a entrada para o Componente Gramatical que, por sua vez, fornece a entrada para o Componente de Saída, em que a mensagem é finalmente articulada.

O Componente Conceitual é responsável pelo desenvolvimento tanto da intenção comunicativa relevante para o evento de fala corrente, quanto das conceitualizações associadas a eventos extralinguísticos relevantes, sendo assim, a força motriz do componente gramatical como um 
todo. O Componente de Saída gera as expressões acústicas ou escritas com base na informação fornecida pelo Componente Gramatical. O Componente Contextual contém a descrição da forma e do conteúdo do discurso precedente, do contexto real do evento de fala e das relações sociais entre os participantes.

Na formulação, o Nível Interpessoal (NI) representa a ação linguística do falante de evocar referentes e atribuir propriedades a fim de conseguir seu objetivo comunicativo. Esse nível é constituído de várias camadas hierárquicas: o Movimento (M), o Ato Discursivo (A), a Ilocução (F), o Conteúdo Comunicado (C) e os subatos Referencial (R) e Atributivo (T). O Ato Discursivo é a unidade básica do discurso e corresponde a uma unidade de entonação, por isso terá sempre uma Ilocução e, de modo geral, um Conteúdo Comunicado. A Ilocução representa uma intenção comunicativa (declarar, questionar, alertar, requerer etc.); já o Conteúdo Comunicativo contém tudo o que o Falante deseja evocar na interação com o Ouvinte, seja por meio de Subatos Atributivos para evocar uma propriedade, como correr, bonito, azul, seja por meio de Subatos Referenciais, para evocar entidades, como caderno, cidade, festa, crença, ideia, razão.

Já o Nível Representacional (NR) trata dos aspectos semânticos das unidades linguísticas, quer referentes ao mundo extralinguístico que ela descreve, quer aos significados de unidades lexicais. A maior unidade hierárquica é o Conteúdo Proposicional (p), um construto mental, que pode conter um ou mais Episódios (ep - conjuntos de Estados de Coisas). Um Estado de Coisas (e) é estruturado sobre uma Propriedade Configuracional (Configuracional property $-\mathrm{f}^{\mathrm{c}}$ ), uma combinação de unidades semânticas sem relação hierárquica entre elas, de modo geral, constituída do predicado e seus argumentos.

Na operação de codificação, o Nível Morfossintático (NM) tem como tarefa tomar o input duplo resultante da formulação dos níveis interpessoal e representacional e fazê-lo emergir em uma única representação estrutural. Igualmente aos níveis da formulação, os níveis da codificação são compostos por camadas hierárquicas: o Nível Morfossintático contém as camadas da Expressão Linguística (Linguistic Expression - Le), da oração (Clause - Cl), do sintagma (Phrase - Xp) e da palavra (Word - W), e o Nível Fonológico (NF) contém o enunciado (Utterance- U), a Frase Entonacional (Intonational Phrase - IP), a Frase Fonológica (Phonological Phrase- PP), o pé e a sílaba.

Nesse modelo, a coordenação é o reflexo morfossintático de uma estratégia discursiva, que combina, no Nível Interpessoal, dois ou mais Atos Discursivos equipolentes (com igual estatuto comunicativo). Desse modo, para a GDF, a Coordenação é um fenômeno que se manifesta na camada da Expressão Linguística, em que se combinam duas unidades, que podem ser usadas independentemente. Assim, em (26), a Expressão Linguística Os Celtic venceram e os Rangers perderam é constituída de duas unidades independentes, Os Celtic venceram e os Rangers perderam, ligadas pela palavra gramatical $e$, conforme representado em (26a).

(26) Celtic won and Rangers lost. (Hengeveld/Mackenzie 2008: 309)

'Os Celtic venceram e os Rangers perderam.'

(26a) ( $\left(\mathrm{Le}_{1}:\left[\left(\mathrm{Cl}_{1}\right)\left(\mathrm{Gw}_{1}\right)\left(\mathrm{Cl}_{2}\right)\right]\left(\mathrm{Le}_{1}\right)\right)$

É possível também ocorrências como (27), em que a coordenação acontece sem a expressão da conjunção (Grammatical word - GW). Nesse caso, a representação é como em (27a). 
(27) Os Celtic venceram, os Rangers perderam.

(27a) (Le $\left.1:\left[\left(\mathrm{Cl}_{1}\right)\left(\mathrm{Cl}_{2}\right)\right]\left(\mathrm{Le}_{1}\right)\right)$

Numa única Expressão Linguística, pode ocorrer a combinação de Sintagmas e/ou de Palavras, em que a lista não pode ser interpretada como uma oração incompleta, já que se trata de Atos Discursivos. Nesse caso, o fenômeno é denominado Listagem, como em (28), com a Expressão Linguística marcada em negrito.

(28) (Can I take your order?) A Big Mac, French fries, and a Coke. (Hengeveld/ Mackenzie 2008: 309)

'(Qual é o seu pedido?) Um Big Mac, batatas fritas e uma Coca.'

Keizer (2015: 178) observa que, no Nível Morfossintático, cada unidade pode conter um número infinito de outras unidades da mesma camada, conforme exemplificado em (29), constituindo o que a autora denomina de stacking 'empilhamento'. Como se pode notar, stacking, de certa forma, retoma a multiplicação direta de constituintes suboracionais de Dik (1997b), uma vez que depende do molde de predicação da propriedade comprar, em que a posição de Undergoer (U) é multiplicada por cinco.

(29) John bought [two apples, three bananas, two pears, six kiwis, some strawberries...] (Keizer 2015: 178)

'João comprou duas maçãs, três bananas, duas peras, seis kiwis, alguns morangos.'

Mackenzie (2018: 49), por outro lado, considera que a coordenação em (30) também se origina no Nível Interpessoal. Trata-se, segundo ele, da coordenação de unidades que compõem o Ato Discursivo. Nesse caso, o processo envolve a ocorrência múltipla de Subatos marcados por funções pragmáticas, de Tópico ou de Foco. Em (30), Bill é um Tópico, enquanto deu e hoje podem ou não ser Foco (isso depende do contexto anterior e das informações compartilhadas entre o Falante e Ouvinte); de qualquer forma, estes e você, aqueles e mim são todos Focos, e é isto que permite a gramaticalidade de (30), apesar de estes a você e aqueles a mim não serem constituintes sintáticos.

(30) Bill gave you these and me those today. (Mackenzie 2018: 49)

'O Bill deu estes a você e aqueles a mim hoje.'

\section{Uma proposta para a coordenação na GDF}

Como fica claro na seção 3, são comumente tratadas as relações aditiva e adversativa, respectivamente representadas por e e mas, recebendo menor atenção a relação alternativa, marcada por ou. Pretendemos, neste estudo, preencher essa lacuna, tratando das três relações Aditiva, Alternativa e Adversativa - respectivamente marcadas por e, ou e mas. ${ }^{8}$

\footnotetext{
${ }^{8}$ As ocorrências utilizadas para exemplificação são extraídas dos capítulos: Coordenação oracional aditiva (Camacho et al. 2021), Coordenação oracional alternativa (Gasparini-Bastos/Parra-Araújo/Souza-Martins 2021); Coordenação oracional adversativa (Garcia et al. 2021), Coordenação não oracional aditiva (Comparini/Guiraldelli/Silva 2021), Coordenação não oracional alternativa (Hattnher/Nagamura/Nuss 2021) e Coordenação não oracional adversativa (Pezatti/Galvão Passetti 2021), que compõem o livro Construções coordenadas nas variedades portuguesas: uma abordagem discursivo-funcional, organizado por Pezatt/Camacho/Hattnher (2021).
} 
Nossa proposta é a de que as diferentes relações derivam de interações diferentes entre os níveis interpessoal e representacional. No caso da Aditiva e da Alternativa, trata- se no Nível Interpessoal de unidades em equipolência, diferenciando-se as duas só no Nível Representacional: a coordenação Aditiva, representada no Nível Morfossintático por e, e a Alternativa por ou, assemelham-se a relações lógico-matemáticas, e por isso distinguem-se no Nível Representacional. A adversativa expressa por mas, por seu turno, indica simultaneamente concessividade no Nível Interpessoal (NI) e adição no Nível Representacional (NR), quer dizer, a palavra mas expressa a combinação NI: Conc + NR: Adição. Essa dupla propriedade se reflete na correlação não só... mas também, tradicionalmente denominada aditiva, nas gramáticas de referência do português.

Hengeveld/Mackenzie (2008), como vimos, limitam-se a tratar a Coordenação como reflexo morfossintático de uma estratégia discursiva, sem considerarem o papel do Nível Representacional. Em nossa proposta, dedicaremos igual atenção aos níveis Interpessoal, Representacional e Morfossintático.

As ocorrências (31) e (32) ilustram como se combinam, no Nível Interpessoal, dois ou mais Atos Discursivos equipolentes; no Nível Representacional serão distinguidas como respectivamente aditiva e alternativa. Diferentemente, a adversativa marcada por mas combina também Atos Discursivos, porém, numa relação de dependência, já que o falante atribui estatutos comunicativos diferentes a cada um deles, havendo assim um Ato Discursivo Nuclear, com maior peso comunicativo, e um Ato Discursivo Subsidiário, que terá a função retórica Concessão, como em (33).

(31) claro que aqueles timorenses que nasceram já depois, bom, eu estou a fazer uma pergunta desnecessária, porque estes rapazes já nasceram depois da invasão e sentem-se sempre timorenses, não é, (TL95:IdentidadePovo)

(32) mas fazem um aborto legal. há também quando uma pessoa fica grávida, e há qualquer distúrbio dentro de, dentro do útero, quer dizer, a criança pode nascer com qualquer anormalidade, ou a criança pode prejudicar a mãe durante o parto... (GB95:Aborto)

(33) não, não gosto de jogo de bicho não. é um jogo muito legal mas eu não me adapto muito, não. (BR80:OJogodoBicho)

Trataremos de cada relação separadamente, começando pelas que envolvem Atos Discursivos equipolentes, a aditiva marcada por $e$, e a disjuntiva, por $o u$, deixando por último a adversativa indicada por mas, que envolve a dependência entre dois Atos Discursivos.

\subsection{Aditiva}

A relação Aditiva, em português, é marcada pela palavra gramatical $e$, herança da forma et do latim clássico (cf. Maurer Jr. 1959 apud Longhin/Pezatti/Novaes-Marques 2019: 49). De um ponto de vista lógico, $e$ equivale ao operador $\wedge$; assim, a relação entre as duas orações, exemplificada em (34), tem uma representação lógica equivalente a $[\mathrm{A} \wedge \mathrm{B}]$, em que o valor de $[\mathrm{A} \wedge$ B] será verdadeiro, se tanto A quanto B sozinhas forem verdadeiras, e falso, em qualquer outro caso. 
(A) também eu gosto muito da música e (B) eu quero ver a música desenvolver em São Tomé. (TP96:Abanda).

O cálculo sentencial, no entanto, é uma explicação extremamente limitada dos usos da língua em seu contexto social, cuja complexidade extrapola, na maioria dos casos, uma análise baseada nos valores de uma tabela de base funcional-veritativa (Camacho 1999: 352). Segundo Sweetser (1990: 93), a lógica é uma metalinguagem construída e é claramente derivada da língua natural, por isso é um contrassenso analisar expressões da língua natural como se fossem idênticas às da lógica.

Assumimos, com Hengeveld/Mackenzie (2008), que, no Nível Interpessoal, a Coordenação (Aditiva e Alternativa) é uma estratégia discursiva que combina dois ou mais Atos Discursivos equipolentes, que constituem o núcleo de um Movimento, conforme ilustra o exemplo (35) e sua representação em (35a). Nesse caso, cada um dos Atos Discursivos combinados ( $\mathrm{A}_{\mathrm{I}}$ e $\left.\mathrm{A}_{\mathrm{J}}\right)$ contém um Conteúdo Comunicativo que, por sua vez, contém vários Subatos, Atributivo (T) e Referencial (R).

(35) claro que aqueles timorenses que nasceram já depois, bom, eu estou a fazer uma pergunta desnecessária, porque estes rapazes já nasceram depois da invasão $\underline{\mathbf{e}}$ sentem-se sempre timorenses, não é?, (TL95:IdentidadePovo)

(35a) (M: [( $\mathrm{A}_{\mathrm{I}}$ : -esses rapazes já nasceram depois da invasão- $\left.\left(\mathrm{A}_{\mathrm{I}}\right)\right)\left(\mathrm{A}_{\mathrm{J}}\right.$ : -sentem-se sempre timorenses- $\left.\left.\left(\mathrm{A}_{\mathrm{J}}\right)\right)\right]\left(\left(\mathrm{M}_{\mathrm{I}}\right)\right)^{9}$

Na Adição, os Atos Discursivos equipolentes se juntam, assemelhando-se a relações "lógicomatemáticas", o que indica tratar-se de uma relação semântica e, portanto, do Nível Representacional, conforme mostra (35b). O operador aditivo $\wedge$ acionará, no Nível Morfossintático, a palavra gramatical $e / \mathrm{i} /$ antecedendo a camada que especifica, como em $(35 \mathrm{c}) \cdot{ }^{10}$

(35b) NR: ( $\mathrm{p}_{\mathrm{i}}$ :-esses rapazes já nasceram depois da invasão- $\left.\left(\mathrm{p}_{\mathrm{i}}\right)\right)\left(\wedge \mathrm{p}_{\mathrm{j}}\right.$ :-sentem-se sempre timorenses- $\left.\left(\mathrm{p}_{\mathrm{j}}\right)\right)$

(35c) NM: (Le $\mathrm{i}:\left[\left(\mathrm{Cl}_{\mathrm{i}}:-\right.\right.$-esses rapazes já nasceram depois da invasão- $\left.\left(\mathrm{Cl}_{\mathrm{i}}\right)\right)\left[\left(\mathrm{Gw}_{\mathrm{i}}\right.\right.$ : /i/ $\left.\left(\mathrm{Gw}_{\mathrm{i}}\right)\right)$ $\left(\mathrm{Cl}_{\mathrm{j}}\right.$ : -sentem-se sempre timorenses- $\left.\left.\left.\left(\mathrm{Cl}_{\mathrm{j}}\right)\right)\right]\left(\mathrm{Le}_{\mathrm{i}}\right)\right)$

O Conteúdo Comunicativo dos Atos Discursivos combinados pode, no entanto, conter apenas um Subato (Atributivo ou Referencial), conforme exemplifica (36) e se representa em (36a). Nesse caso, há, no Nível Representacional, vários Estados de Coisas (e), como em (36b), e, no

\footnotetext{
${ }^{9}$ Considerando que a descrição de dados em córpus não precisa ser mais exaustiva do que o necessário para a análise, a GDF fornece a possibilidade de simplificar formalmente aspectos não essenciais de suas representações, tendo em vista centrar-se nas questões essenciais. Quando nem todos os detalhes são necessários para a análise do fenômeno em questão, usa-se um símbolo especial (-) para indicar o início e o fim de um fragmento que não é analisado em detalhe. Neste artigo, por razões didáticas, vamos inserir os fragmentos na posição que lhes corresponde em cada nível, ao passo que no modelo GDF só se inserem em cada nível os elementos que lhe pertencem. É só no NM que os elementos complementares do NI e do NR se juntam numa sequência linearmente ordenada.

${ }^{10}$ Utilizamos o símbolo $\wedge$ para representar o operador de adição do Nível Representacional. Como Operador $(\pi)$ se aplica a uma unidade em si mesma, o símbolo lógico é indicado antes da variável que especifica na estrutura geral das camadas dentro dos níveis, conforme a seguinte representação geral: $\left(\boldsymbol{\pi} \mathrm{v}_{1}:\left[\mathrm{H}\left(\mathrm{v}_{1}\right)_{\varphi}\right]:\left[\sigma\left(\mathrm{v}_{1}\right)_{\varphi}\right]\right)_{\varphi}$ (Hengeveld/Mackenzie 2012: 50).
} 
Nível Morfossintático, a Expressão Linguística é formada por sintagmas ou palavras, o que se denomina de Listagem, conforme representada em (36c) .

(36) Cuba em mil novecentos e cinquenta e sete o que é que era? Reduto de americano; prostituição; contrabando de drogas e miséria. (BR87:EconomiaSociedade) $)^{11}$

(36a) $\left(\mathrm{M}_{\mathrm{I}}\right.$ : $\left[\left(\mathrm{A}_{\mathrm{I}}:\left(\mathrm{C}_{\mathrm{I}}:\left(\mathrm{R}_{\mathrm{I}}-\right.\right.\right.\right.$ reduto de americano- $\left.\left.\left.\left.\left(\mathrm{R}_{\mathrm{I}}\right)\right)\left(\mathrm{C}_{\mathrm{I}}\right)\right)\left(\mathrm{A}_{\mathrm{I}}\right)\right)\right]\left[\left(\mathrm{A}_{\mathrm{J}}:\left(\mathrm{C}_{\mathrm{J}}:\left(\mathrm{R}_{\mathrm{J}}-\right.\right.\right.\right.$ prostituição$\left.\left.\left.\left.\left(\mathrm{R}_{\mathrm{J}}\right)\right)\left(\mathrm{C}_{\mathrm{J}}\right)\right)\left(\mathrm{A}_{\mathrm{J}}\right)\right)\right]\left[\left(\mathrm{A}_{\mathrm{K}}:\left(\mathrm{C}_{\mathrm{K}}:\left(\mathrm{R}_{\mathrm{K}}-\right.\right.\right.\right.$ contrabando de drogas$\left.\left.\left.\left.-\left(\mathrm{R}_{\mathrm{K}}\right)\right)\left(\mathrm{C}_{\mathrm{K}}\right)\right)\left(\mathrm{A}_{\mathrm{K}}\right)\right)\right]\left[\left(\mathrm{A}_{\mathrm{L}}:\left(\mathrm{C}_{\mathrm{L}}\right.\right.\right.$ : $\left(\mathrm{R}_{\mathrm{L}}-\right.$ miséria $\left.\left.\left.\left.\left.-\left(\mathrm{R}_{\mathrm{L}}\right)\right)\left(\mathrm{C}_{\mathrm{L}}\right)\right)\left(\mathrm{A}_{\mathrm{L}}\right)\right)\right]\left(\mathrm{M}_{\mathrm{I}}\right)\right)$

(36b) ( $\mathrm{e}_{\mathrm{i}}:\left(\mathrm{l}_{\mathrm{i}}:\left(\mathrm{f}_{\mathrm{i}}:-\right.\right.$ reduto de americano- $\left.\left.\left(\mathrm{f}_{\mathrm{i}}\right)\right)\left(\mathrm{l}_{\mathrm{i}}\right)\right)\left(\mathrm{e}_{\mathrm{i}}\right)\left(\& \mathrm{e}_{\mathrm{j}}:\left(\mathrm{f}_{\mathrm{j}}:-\right.\right.$ prostituição- $\left.\left.\left(\mathrm{f}_{\mathrm{j}}\right)\right)\left(\mathrm{e}_{\mathrm{j}}\right)\right)\left(\& \mathrm{e}_{\mathrm{k}}\right.$ : $\left(\mathrm{f}_{\mathrm{k}}\right.$ : - contrabando de drogas- $\left.\left.\left(\mathrm{f}_{\mathrm{k}}\right)\right)\left(\mathrm{e}_{\mathrm{k}}\right)\right)\left(\& \mathrm{e}_{\mathrm{l}}:\left(\mathrm{f}_{\mathrm{l}}\right.\right.$ : -miséria- $\left.\left.\left(\mathrm{f}_{\mathrm{l}}\right)\right)\left(\mathrm{e}_{\mathrm{l}}\right)\right)$

(36c) (Lei: $\left[\left(\mathrm{Np}_{\mathrm{i}}\right.\right.$ : -reduto de americano- $\left.\left(\mathrm{Np}_{\mathrm{i}}\right)\right)\left(\mathrm{Np}_{\mathrm{j}}\right.$ : $\left(\mathrm{Nw}_{\mathrm{i}}\right.$ : prostituição $\left.\left.\left(\mathrm{Nw}_{\mathrm{i}}\right)\right)\left(\mathrm{Np}_{\mathrm{j}}\right)\right)\left(\mathrm{Np}_{\mathrm{k}}:-\right.$ contrabando de drogas- $\left.\left(\mathrm{Np}_{\mathrm{k}}\right)\right)\left(\mathrm{Gw}_{\mathrm{i}}\right.$ : /i/ $\left.\left(\mathrm{Gw}_{\mathrm{i}}\right)\right)\left(\mathrm{Np}_{\mathrm{l}}\right.$ : $\left(\mathrm{Nw}_{\mathrm{l}}\right.$ : miséria $\left.\left.\left.\left(\mathrm{Nw}_{\mathrm{l}}\right)\right)\right]\left(\mathrm{Le}_{\mathrm{i}}\right)\right)$

Como vimos, para Dik (1997b: 194), a coordenação pode ocorrer entre constituintes suboracionais. Assim, ao lado da coordenação de orações, há a coordenação local de constituintes, o que acontece na situação em que o Falante, ao chegar a um certo nicho (slot) da construção de uma oração, multiplica-o localmente, resultando numa série coordenada de itens da mesma função. Nesse caso, a coordenação obedece a uma regra que multiplica constituintes suboracionais na posição que eles ocupam na estrutura da oração.

Em termos de GDF, isso significa que é possível a combinação de unidades, que, no Nível Representacional, correspondem, por exemplo, a argumentos de uma predicação. Desse modo, em (37), são combinados argumentos do predicado informar, que, no Nível Interpessoal, correspondem a Conteúdos Comunicativos.

então tu para chegares lá para informar a[à] população que a SIDA é uma doença contagiosa, e pode-se transmitir através aquilo, tu não vais ter um meio de lhe explicares, se não saber a base, como entrar... (GB95:SIDA)

(37a) NI: $\quad\left(\mathrm{C}_{\mathrm{I}}:\left[\left(\mathrm{T}_{\mathrm{I}}\right.\right.\right.$ - informar- $\left.\left(\mathrm{T}_{\mathrm{I}}\right)\right)\left(\mathrm{R}_{\mathrm{I}}\right.$ : - a população- $\left.\left(\mathrm{R}_{\mathrm{J}}\right)\right)\left(\mathrm{C}_{\mathrm{J}}\right.$ : $-\mathrm{a}$ SIDA é uma doença contagiosa- $\left.\left(\mathrm{C}_{\mathrm{J}}\right)\right)\left(\mathrm{C}_{\mathrm{K}}\right.$ : - pode-se transmitir através aquilo- $\left.\left.\left.\left(\mathrm{C}_{\mathrm{K}}\right)\right)\right]\left(\mathrm{C}_{\mathrm{I}}\right)\right)$

Em (37), os dois Conteúdos Proposicionais, a SIDA é uma doença contagiosa e pode-se transmitir através aquilo, ocupam, no Nível Representacional, o nicho de argumento Undergoer do predicado informar. Obviamente, o tipo de categoria semântica do complemento está de acordo com o tipo de predicado envolvido. Em (37), como argumentos do verbo informar, há dois Conteúdos Proposicionais: a SIDA é uma doença contagiosa e pode-se transmitir através aquilo.

(37b) NR: $\quad\left(\mathrm{e}_{\mathrm{i}}:\left[\left(\mathrm{f}_{\mathrm{i}}^{\mathrm{i}}:\left(\mathrm{f}_{\mathrm{i}}\right.\right.\right.\right.$ : -informar $\left.{ }_{\mathrm{V}}-\left(\mathrm{f}_{\mathrm{i}}\right)\right)\left(\mathrm{x}_{\mathrm{i}}\right)_{\mathrm{A}}\left(\mathrm{x}_{\mathrm{j}}-\mathrm{a} \text { população- }\left(\mathrm{x}_{\mathrm{j}}\right)\right)_{\mathrm{L}}\left[\left(\mathrm{p}_{\mathrm{i}}:\left(\mathrm{ep}_{\mathrm{i}}\right.\right.\right.$ : -a SIDA é uma doença contagiosa- $\left.\left.\left(e \mathrm{p}_{\mathrm{i}}\right)\right)\left(\mathrm{p}_{\mathrm{i}}\right)\right)\left(\wedge \mathrm{p}_{\mathrm{j}}:\left(\mathrm{ep}_{\mathrm{j}}\right.\right.$ : - pode-se transmitir através aquilo- $\left.\left(\mathrm{ep}_{\mathrm{j}}\right)\right)$ $\left.\left.\left.\left.\left(\mathrm{pJ}_{\mathrm{J}}\right)\right]_{\mathrm{u}}\right)\left(\mathrm{f}_{\mathrm{i}}^{\mathrm{c}}\right)\right)\left(\mathrm{e}_{\mathrm{i}}\right)\right)$

\footnotetext{
${ }^{11}$ A oitiva desse fragmento mostra que cada unidade, [reduto de americano], [prostituição], [contrabando de drogas] e [miséria], apresenta uma pauta melódica com um movimento tonal localizado em uma (ou mais) sílaba, que permite a interpretação como um todo, sendo cada uma separada por uma pausa menor do que a que separa enunciados (U), consistindo cada qual em uma Frase Entonacional.
} 
(37c) NM: $\left(\mathrm{Cl}_{\mathrm{i}}\right.$ : -informar a população- $\left.\left(\mathrm{Cl}_{\mathrm{i}}\right)\right)\left(\mathrm{Gw}_{\mathrm{i}}\right.$ : que $\left.\left(\mathrm{Gw}_{\mathrm{i}}\right)\right)\left[\left(\mathrm{Cl}_{\mathrm{j}}-\mathrm{a}\right.\right.$ SIDA é uma doença contagiosa- $\left.\left(\mathrm{Cl}_{\mathrm{j}}\right)\right)\left(\mathrm{Gw}_{\mathrm{j}}\right.$ : $\left./ \mathrm{i} /\left(\mathrm{Gw}_{\mathrm{j}}\right)\right)\left(\mathrm{Cl}_{\mathrm{k}}\right.$ :-pode-se transmitir através aquilo- $\left.\left.\left.\left(\mathrm{Cl}_{\mathrm{k}}\right)\right)\right]\left(\mathrm{Cl}_{\mathrm{i}}\right)\right)$ $\left.\left(\mathrm{Le}_{\mathrm{i}}\right)\right)$

Conteúdos Comunicativos podem também corresponder a modificadores de camadas do Nível Representacional. É o que mostra a ocorrência (38).

(38) claro que ao retirar o coberto vegetal, eu estou imediatamente a provocar a situação do surgimento de ravinas. a água da chuva, é, são, zonas que continua a chover intensamente. essa água da chuva cai directamente no solo, desagregando esse solo e arrastando-o depois para os rios. (AN97:GuerraAmbiente)

Em (38), os Conteúdos Comunicativos equipolentes no Nível Interpessoal (veja (38a)) correspondem, no Nível Representacional, a modificadores, desagregando esse solo $e$ arrastando-o depois para os rios, do Estado de Coisas essa água da chuva cai directamente no solo, indicando a consequência da ocorrência desse evento. ${ }^{12}$

(38a) NI: $\quad\left(\mathrm{M}_{\mathrm{I}}\right.$ : [( $\mathrm{A}_{\mathrm{I}}$ : $\left(\mathrm{C}_{\mathrm{I}}\right.$ : -essa água da chuva cai directamente no solo- $\left.\left.\left(\mathrm{C}_{\mathrm{I}}\right)\right)\left(\mathrm{A}_{\mathrm{I}}\right)\right)\left(\left(\mathrm{A}_{\mathrm{J}}\right.\right.$ : $\left(C_{J}\right.$ : -desagrega esse solo- $\left.\left.\left(C_{J}\right)\right)\left(A_{J}\right)\right)\left(A_{K}:\left(C_{K}\right.\right.$ : -arrasta-o depois para os rios- $\left.\left(C_{K}\right)\right)$ $\left.\left.\left(\mathrm{A}_{\mathrm{K}}\right)\right)\right]\left(\mathrm{M}_{\mathrm{I}}\right)$

(38b) NR: $\quad\left(\mathrm{p}_{\mathrm{i}}:\left(\right.\right.$ Pres ep $\mathrm{p}_{\mathrm{i}}:\left(\mathrm{e}_{\mathrm{i}}:\left(\mathrm{f}_{\mathrm{i}}^{\mathrm{c}} \mathrm{i}-\right.\right.$-essa água da chuva cai directamente no solo- $\left.\left(\mathrm{f}_{\mathrm{i}}^{\mathrm{c}}\right)\right)$ : [(Sim $\mathrm{e}_{\mathrm{j}}$-desagregando o solo- $\left.\left(\mathrm{e}_{\mathrm{j}}\right)\right)\left(\wedge \operatorname{Sim}_{\mathrm{k}}\right.$ :-arrastando-o para os rios- $\left.\left.\left.\left.\left(\mathrm{e}_{\mathrm{k}}\right)\right)\right]_{\text {Circ }}\left(\mathrm{f}_{\mathrm{i}}^{\mathrm{c}}\right)\right)\left(\mathrm{e}_{\mathrm{i}}\right)\right)$ $\left.\left.\left(\mathrm{ep}_{\mathrm{i}}\right)\right)\left(\mathrm{p}_{\mathrm{i}}\right)\right)$

(38c) NM: (Lei: $\left[\left(\mathrm{Cl}_{\mathrm{i}}\right.\right.$ : -essa água da chuva cai directamente no solo- $\left.\left(\mathrm{Cl}_{\mathrm{i}}\right)\right)\left({ }^{\mathrm{Dep}} \mathrm{Cl}_{\mathrm{j}}-\right.$ desagregando o solo- $\left.\left(\mathrm{Cl}_{\mathrm{j}}\right)\right)\left(\mathrm{Gw}_{\mathrm{i}}\right.$ : $\left./ \mathrm{i} /\left(\mathrm{Gw}_{\mathrm{i}}\right)\right)\left({ }^{\mathrm{Dep}} \mathrm{Cl}_{\mathrm{k}}\right.$-arrastando-o depois para os rios$\left.\left.\left.\left.\left(\mathrm{Cl}_{\mathrm{k}}\right)\right)\right]\left(\mathrm{Cl}_{\mathrm{i}}\right)\right)\left(\mathrm{Le}_{\mathrm{i}}\right)\right)$

Existem casos em que, no Nível Representacional, há o preenchimento múltiplo de uma das camadas desse nível, geralmente a da predicação, por entidades que correspondem, no Nível Interpessoal, a Subatos da mesma natureza, ou Referenciais ou Atributivos.

Em (39), preenche-se a posição de Actor com dois indivíduos, a senhora e o marido, argumentos do verbo pretender, conforme representação semântica em (39a) e morfossintática em (39b); em (40), ocupam a posição de Undergoer da propriedade de dois lugares perder os Estados de Coisas a sua identidade e o seu orgulho; já em (41), é a posição argumental de Locative (Ablativo) que é preenchida por folga, dança e vinho da propriedade gostar.

(39) a senhora e o marido pretendem fazer o quê? (BR80:ViverComOutros)

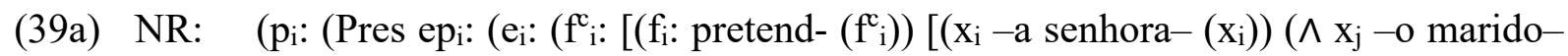
$\left.\left.\left.\left.\left.\left.\left(\mathrm{x}_{\mathrm{j}}\right)\right]_{\mathrm{A}}\left(\mathrm{e}_{\mathrm{j}} \text { :-fazer o quê- }\left(\mathrm{e}_{\mathrm{j}}\right)\right)_{\mathrm{U}}\right]\left(\mathrm{f}_{\mathrm{i}}^{\mathrm{i}}\right)\right)\left(\mathrm{e}_{\mathrm{i}}\right)\right)\left(\mathrm{ep}_{\mathrm{i}}\right)\right)\left(\mathrm{p}_{\mathrm{i}}\right)\right)$

(39b) NM: $\left(\mathrm{Cl}_{\mathrm{i}}\right.$ : $\left[\left(\mathrm{Np}_{\mathrm{i}}-\mathrm{a}\right.\right.$ senhora $\left.\left.-\left(\mathrm{Np}_{\mathrm{i}}\right)\right)(\mathrm{Gw}: / \mathrm{i} /(\mathrm{Gw}))\left(\mathrm{Np}_{\mathrm{j}}-\mathrm{O} \text { marido- }\left(\mathrm{Np}_{\mathrm{j}}\right)\right)_{\mathrm{Sbj}}\right](\mathrm{Vp}$ : pretendem $\left.\left(\mathrm{Vp}_{\mathrm{i}}\right)\right)\left(\mathrm{Cl}_{\mathrm{j}}\right.$ :-fazer o quê- $\left.\left.\left.\left(\mathrm{Cl}_{\mathrm{j}}\right)\right)\right]\left(\mathrm{Cl}_{\mathrm{i}}\right)\right)$

(40) admiro-me bastante porque... foram educados nas escolas indonésias mas não perdem assim a sua identidade e o seu orgulho de ser timorense. (TL99:IdentidadePovo)

(41) os católicos são, sempre foram mais saídos, sempre gostavam da folga e dança e.... vinho (GO01:DiversidadeReligiosa)

\footnotetext{
12 Hengeveld/Mackenzie (2008: 308) chamam este tipo de construção de cossubordinação.
} 
A ocorrência (41) sugere que a categoria semântica das unidades combinadas pode variar, já que aparentemente se combinam dois Estados de Coisas, folga e dança, e um Indivíduo, vinho. Há que se notar, no entanto, que "vinho" se usa aqui metonimicamente no sentido do consumo de vinho. Na GDF pode-se representar facilmente esta metonímia, como se segue: $\left(\mathrm{e}_{\mathrm{i}}\right.$ : $\left(\mathrm{f}_{\mathrm{i}}\right.$ : vinho $\left.\left.\left(f_{i}\right)\right)\left(e_{i}\right)\right)$.

Assim, desde que da mesma função, no Nível Representacional, a posição de modificador pode ser expandida, como em (42), em que à vontade e sem problemas de rasgos restringem o Estado de Coisas nascimento do bebê, ou como em (43), em que os adjetivos, geomorfológicos, vulcanológicos e hidrogeológicos restrigem o núcleo nominal aspecto.

-> [...] e então, a pessoa dava mesmo, tinha mesmo fortes contracções.

- hum, hum.

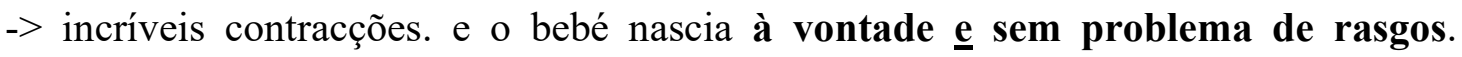
(CV95:ColherPanela) ${ }^{13}$

(43) [...] nós fomos para o Fogo para fazer uma visita de estudos cujo objectivo era ver os aspectos geomorfológicos, vulcanológicos e hidrogeológicos no terreno. (CV95:Ilha Fogo)

Como se vê, a combinação de unidades do Ato Discursivo, correspondentes a argumentos ou modificadores no Nível Representacional, pode, no Nível Morfossintático, ser mapeada por orações, como mostra a representação em (38c); sintagmas, conforme representação em (41b); ou palavras, conforme em (43b). Nesse caso, a camada envolvida é a da Oração, e não a da Expressão Linguística. Keizer (2015: 178) nomeia esse fenômeno de stacking ('empilhamento'). Dessa forma, a diferença entre Listagem e Empilhamento é que a primeira é um fenômeno do Nível Interpessoal, ao passo que a segunda é do Nível Representacional. Por exemplo, os Nps a senhora e o marido constitui um único Subato Referencial, que é expandido no Nível Representacional para ocupar o nicho de Ator na Propriedade Configuracional formada com o predicado pretender. Na Listagem, há consequências fonológicas, visto que cada membro equivale a uma Frase Entonacional, enquanto no Empilhamento, cada unidade corresponde a uma frase fonológica.

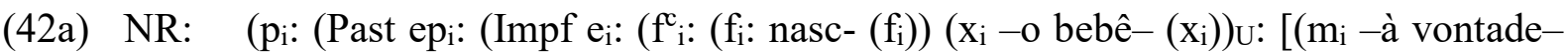
$\left.\left(\mathrm{m}_{\mathrm{i}}\right)\right)\left(\wedge \mathrm{m}_{\mathrm{j}}:-\right.$-sem problemas de rasgos- $\left.\left.\left.\left.\left.\left.\left(\mathrm{m}_{\mathrm{j}}\right)\right)\right]_{\text {Manner }}\left(\mathrm{f}_{\mathrm{i}}\right)\right)\left(\mathrm{e}_{\mathrm{i}}\right)\right)\left(\mathrm{ep}_{\mathrm{i}}\right)\right)\left(\mathrm{p}_{\mathrm{i}}\right)\right)$

(42b) NM: $\left(\mathrm{Cl}_{\mathrm{i}}:\left(\mathrm{Np}_{\mathrm{i}}-\mathrm{o} \text { bebê- }-\left(\mathrm{Np}_{\mathrm{i}}\right)\right)_{\mathrm{Sbj}}\left(\mathrm{Vp}_{\mathrm{i}}-\right.\right.$ nascia $\left.-\left(\mathrm{Vp}_{\mathrm{i}}\right)\right)$ [(Adp $\mathrm{A}_{\mathrm{i}}$ - -à vontade- $\left.\left(\mathrm{Adp}_{\mathrm{i}}\right)\right)$ $(\mathrm{Gw}: / \mathrm{i} /(\mathrm{Gw}))\left(\mathrm{Adp}_{\mathrm{j}}-\mathrm{sem}\right.$ problemas de rasgos- $\left.\left.\left.\left(\mathrm{Adp}_{\mathrm{j}}\right)\right)\right]\left(\mathrm{Cl}_{\mathrm{i}}\right)\right)$

(43a) NR: $\quad\left(e_{i}:\left(f_{i}:\left(\left(f_{i}:\right.\right.\right.\right.$ vê- $\left.\left(f_{i}\right)\right)\left(x_{i}\right)_{A}\left[\left(m e_{j}:\left(f_{j}:\right.\right.\right.$ aspecto $\left.\left.\left(f_{j}\right)\right)\left(e_{j}\right)\right):\left[\left(f_{k}\right.\right.$ : geológico $\left.\left(f_{k}\right)\right)\left(\wedge f_{1}\right.$ : vulcanológico $\left.\left(f_{l}\right)\right)\left(\wedge f_{k}\right.$ : hidrogeológico $\left.\left.\left.\left.\left.\left.\left.\left(f_{k}\right)\right)\right]\left(e_{j}\right)\right):\left(l_{i}:- \text { no terreno- }\left(l_{i}\right)\right)_{L o c}\left(e_{j}\right)\right)\right]_{U}\right)\left(f^{f_{i}}\right)\right)$ $\left.\left(\mathrm{e}_{\mathrm{i}}\right)\right)$

(43b) NM: $\left(\mathrm{Cl}_{\mathrm{i}}:\left[\left(\mathrm{Vp}_{\mathrm{i}}: \operatorname{ver}\left(\mathrm{Vp}_{\mathrm{i}}\right)\right)\left(\mathrm{Np}_{\mathrm{i}}:\left[\left(\left(\mathrm{Gw}_{\mathrm{i}}:\right.\right.\right.\right.\right.\right.$ os $\left.\left(\mathrm{Gw}_{\mathrm{i}}\right)\right)\left(\mathrm{Nw}_{\mathrm{i}}\right.$ : aspectos $\left(\mathrm{Nw}_{\mathrm{i}}\right)\left(\mathrm{Adjw}_{\mathrm{i}}\right.$ : geológicos $\left.\left(\operatorname{Adjw}_{\mathrm{i}}\right)\right)\left(\operatorname{Adjw}_{\mathrm{j}}\right.$ : vulcanológicos $\left.\left(\operatorname{Adjw}_{\mathrm{j}}\right)\right)\left(\mathrm{Gw}_{\mathrm{j}}: / \mathrm{i} /\left(\mathrm{Gw}_{\mathrm{j}}\right)\right)\left(\operatorname{Adjw}_{\mathrm{k}}\right.$ : hidrogeológicos $\left.\left(\operatorname{Adjw}_{\mathrm{k}}\right)\right)\left(\mathrm{Adp}_{\mathrm{i}}\right.$ : -no terreno- $\left.\left.\left.\left.\left(\mathrm{Adp}_{\mathrm{i}}\right)\right)\right]\left(\mathrm{Np}_{\mathrm{i}}\right)\right]\left(\mathrm{Cl}_{\mathrm{i}}\right)\right)$

A análise mostra que a combinação de unidades por meio de $e$ estabelece uma operação aritmética de soma, e por isso vem do Nível Representacional. Em outras palavras, a

13 Os sinais -> e - indicam mudança de turno entre os falantes: -> indica F1, e - indica F2. 
coordenação por meio de $e$ descreve estruturas linguísticas em termos da denotação. Desde que tenham equivalência funcional, teoricamente não há limite para o número de unidades coordenadas. Matematicamente trata-se de $1+2+3+4(+n)$, que pode ser representado morfossintaticamente por 1 e 2 e 3 e 4; na maioria dos casos, no entanto, aplica-se simplesmente uma regra de expressão que impõe que $e$ apareça antes do último membro da lista: 1, 2, 3 e 4 .

\subsection{Alternativa}

A relação alternativa, assim como a aditiva, tem encontrado explicação na lógica, por meio de um raciocínio, que busca construir sentenças complexas a partir de sentenças mais simples, utilizando valores de verdade de sentenças combinadas (A e B) para se chegar ao valor de verdade da sentença resultante, mais complexa do que as primeiras. Desse modo, quando as sentenças constituintes são ligadas pelo operador lógico $V$, que marca uma relação de disjunção, é possível encontrar os seguintes valores de verdade para as sentenças resultantes:

\begin{tabular}{|l|l|l|}
\hline A & B & AVB \\
\hline V & V & V \\
\hline V & F & V \\
\hline F & V & V \\
\hline F & F & F \\
\hline
\end{tabular}

Figura 3: Tabela verdade na relação disjuntiva (Pezatti/Longhin 2016: 21)

Por esse ponto de vista, as sentenças podem ser avaliadas unicamente como verdadeiras (V) ou falsas (F), e, na relação de disjunção, basta que uma das sentenças constituintes seja verdadeira para que a sentença resultante também o seja, como no caso de (44).

(44) A senhora acha que há diferença entre um e outro ou todos são do mesmo tipo? (DID-SP-234:228).

A última linha da Figura 3 mostra uma combinação possível para a lógica, mas inadequada do ponto de vista da língua enquanto instituição social, já que infringe os princípios comunicativos, conforme bem observa Sweetser (1990: 93). Segundo a autora, para garantir a informatividade do enunciado, o falante, ao formular uma relação alternativa, considera que pelo menos um dos membros combinados é verdadeiro.

Neves (2000); Ilari/Neves (2008) e Pezatti/Longhin (2016) distinguem, por outro lado, a disjunção inclusiva e a exclusiva, considerando que, nas línguas naturais, é possível a formulação de relações alternativas em que as duas opções oferecidas possam ocorrer juntas, formando uma disjunção inclusiva; ou relações alternativas em que apenas uma das opções é verdadeira, caracterizando a disjunção exclusiva.

Concordamos, no entanto, com a afirmação de Sweetser (1990: 93) de que o sentido literal de uma relação alternativa é sempre exclusivo, já que a produção de uma relação alternativa implica que o falante desconhece quais das opções é a verdadeira, e, ao mesmo tempo, assume que pelo menos uma é a correta. Em outras palavras, considerando-se o postulado de Grice 
(1975) de que na comunicação deve-se ser o mais informativo possível, não se espera que o falante produza "X ou Y", se ele tem condições de realizar um enunciado do tipo "X e Y". Sweetser (1990: 93) não nega, todavia, a possibilidade de uma leitura inclusiva das relações alternativas, mas defende que essa relação de inclusão é conversacional e influenciada pelo contexto, pois o simples uso de ou não é suficiente para inferir a noção de inclusão, o que, segundo Sweetser (1990: 93), diferencia o uso da conjunção ou do operador lógico $\vee$, já que, ao contrário do operador lógico, "ou normalmente veicula a expectativa de que apenas uma das opções expressas será de fato a opção correta". ${ }^{14}$

Segundo Pezatti (1999: 413), o sistema de conjunções disjuntivas, na evolução do latim para o português, apresentou uma redução no seu inventário. Havia duas conjunções para assinalar a disjunção: aut e vel. Aut, além de mais frequente, expressava disjunção exclusiva, enquanto vel expressava disjunção inclusiva. Com a evolução do português, vel desapareceu por completo, e aut originou ou. Desse modo, uma única conjunção - ou - ficou responsável por marcar dois sentidos que eram representados por formas distintas em latim. Como não há uma diferença morfossintática que indique se o sentido da relação alternativa marcada por ou é inclusivo ou exclusivo, cabe ao contexto determinar qual dos dois sentidos prevalece (Pezatti/Longhin 2016: 41). Dada a ambiguidade no uso simples de ou, a língua portuguesa encontra, no uso correlativo dessa conjunção (ou ... ou ), uma estratégia para garantir a interpretação exclusiva da relação alternativa, conforme vemos em (45):

(45) é um controle muito natural ou você não tem filhos ou vai ser é castrado (EF-RJ379:205)

Para Sweetser (1990), as relações de alternância podem ocorrer em três domínios: no domínio do conteúdo, no epistêmico e no dos atos de fala, conforme ilustram respectivamente (46), (47) e (48):

(46) Every Sunday, John eats pancakes or fried eggs. (Sweetser 1990: 93)

'Todo domingo, João come panquecas ou ovos fritos.'

(47) John is home, or somebody is picking up his newspapers. (Sweetser 1990: 94)

'O João está em casa, ou alguém está recolhendo seus jornais.'

(48) Have an apple turnover, or would you like a strawberry tart? (Sweetser 1990: 95) 'Pegue um folhado de maçã, ou você prefere uma torta de morango?'

Como vimos, a Coordenação é o reflexo morfossintático de uma estratégia discursiva, que combina, no Nível Interpessoal, dois ou mais Atos Discursivos equipolentes, que compõem o núcleo de um Movimento. A ocorrência (49) ilustra exatamente isso: há dois Atos Discursivos, a criança pode nascer com qualquer anormalidade e a criança pode prejudicar a mãe durante o parto, de igual estatuto comunicativo, já que implica que o falante desconhece qual das opções apresentadas é a verdadeira, ao mesmo tempo em que assume que as opções oferecidas não são simultaneamente corretas. A representação interpessoal de (49) encontra-se em (49a), enquanto (49b) apresenta a do Nível Representacional e (49c) a morfossintática.

\footnotetext{
${ }^{14}[\ldots]$ or normally carries with it an expectation that only one of the expressed options will in fact be the correct one.
} 
(49) quer dizer, a criança pode nascer com qualquer anormalidade, ou a criança pode prejudicar a mãe durante o parto... (GB95:Aborto)

(49a) NI: $\quad\left(\mathrm{M}_{\mathrm{I}}\right.$ : [( $\mathrm{A}_{\mathrm{I}}$ : $-\mathrm{a}$ criança pode nascer com qualquer anormalidade- $\left.\left(\mathrm{A}_{\mathrm{I}}\right)\right)\left(\mathrm{A}_{\mathrm{J}}\right.$ : $-\mathrm{a}$ criança pode prejudicar a mãe durante o parto- $\left.\left.\left(\mathrm{A}_{\mathrm{J}}\right)\right)\right]\left(\left(\mathrm{M}_{\mathrm{I}}\right)\right)$

(49b) NR: ( $\quad \mathrm{p}_{\mathrm{i}}$ : (Pres ep $\mathrm{p}_{\mathrm{i}}:\left(\mathrm{e}_{\mathrm{i}}-\mathrm{a}\right.$ criança pode nascer com qualquer anormalidade- $\left.\left.\left(\mathrm{e}_{\mathrm{i}}\right)\right)\left(\mathrm{e} \mathrm{p}_{\mathrm{i}}\right)\right)$ $\left.\left(p_{i}\right)\right)\left(\vee p_{j}:\left(\right.\right.$ Pres ep $p_{j}:\left(e_{j}:-a\right.$ criança pode prejudicar a mãe durante o parto- $\left.\left.\left(e_{j}\right)\right)\left(e p_{j}\right)\right)$ $\left.\left(\mathrm{p}_{\mathrm{j}}\right)\right)$

(49c) NM: (Le $\mathrm{i}:\left[\left(\mathrm{Cl}_{\mathrm{i}}:-\mathrm{a}\right.\right.$ criança pode nascer com qualquer anormalidade- $\left.\left(\mathrm{Cl}_{\mathrm{i}}\right)\right)\left(\mathrm{Gw}_{\mathrm{i}}\right.$ : /ow $/$ $\left.\left(\mathrm{Gw}_{\mathrm{i}}\right)\right)\left(\mathrm{Cl}_{\mathrm{j}}\right.$ :-a criança pode prejudicar a mãe durante o parto- $\left.\left.\left.\left(\mathrm{Cl}_{\mathrm{j}}\right)\right)\right]\left(\mathrm{Le}_{\mathrm{i}}\right)\right)$

Assim como ocorre com a aditiva, é possível a combinação de dois ou mais Atos Discursivos equipolentes unidos por ou, cujo Conteúdo Comunicativo é constituído de um único Subato, como em (50).

(50) Doc.: tem algum outro que cê sabe?

Inf.: ...uhm::...eu-a-cho-que-nã::o... que tipo de jogo você fala assim jogos assim ou jogo de por exemplo bola queima::da $(\mathrm{AC}-006)^{15}$

Nessa ocorrência, o informante responde à solicitação do documentador de falar sobre jogos, pedindo-lhe, por meio de outra pergunta, que ele especifique a pergunta. Em seguida, oferece alternativas de tipos de jogos: jogos assim (assim se refere ao jogo de dominó) ou jogo de bola. Cada uma dessas alternativas representa uma contribuição completa para o Movimento em desenvolvimento, sem que haja uma dependência entre elas (Hattnher/Nagamura/Nuss 2021: 237). Há, portanto, dois Atos Discursivos equipolentes, como se representa em (50a), que correspondem, no Nível Representacional, a dois Estados de Coisas, conforme (50b), que, no Nível Morfossintático, são mapeados por dois sintagmas nominais, formando juntos uma Expressão Linguística, como mostra (50c). Trata-se, portanto, de Listagem.

(50a) NI: $\quad\left(\mathrm{M}_{\mathrm{I}}:\left[\left(\mathrm{A}_{\mathrm{I}}:-\right.\right.\right.$ jogos assim- $\left.\left(\mathrm{A}_{\mathrm{I}}\right)\right)\left(\mathrm{A}_{\mathrm{J}}\right.$ : -jogo de por exemplo bola queimada- $\left.\left.\left(\mathrm{A}_{\mathrm{J}}\right)\right)\right]$ $\left.\left(\mathrm{M}_{\mathrm{I}}\right)\right)$

(50b) NR: ( $\mathrm{e}_{\mathrm{i}}$ : - jogos assim- $\left.\left(\mathrm{e}_{\mathrm{i}}\right)\right)\left(\mathrm{V}\left(\mathrm{e}_{\mathrm{j}}\right.\right.$ : -jogo por exemplo de bola queimada- $\left.\left(\mathrm{e}_{\mathrm{j}}\right)\right)$

(50c) NM: (Le $\mathrm{i}:\left[\left(\mathrm{Np}_{\mathrm{i}}:-\right.\right.$ jogos assim- $\left.\left(\mathrm{Np}_{\mathrm{i}}\right)\right)\left(\mathrm{Gw}_{\mathrm{i}}\right.$ : /ow/ $\left.\left(\mathrm{Gw}_{\mathrm{i}}\right)\right)\left(\mathrm{Np}_{\mathrm{j}}\right.$ : -jogo por exemplo de bola queimada- $\left.\left.\left.\left(\mathrm{Np}_{\mathrm{j}}\right)\right)\right]\left(\mathrm{Le}_{\mathrm{i}}\right)\right)$

A junção alternativa, da mesma forma que a aditiva, pode combinar constituintes que, no Nível Representacional, ocupam o mesmo nicho (slot) no molde de predicação. É o que revela (51), em que se é verdade e se é mentira ocupam a posição de Undergoer do predicado saber, consistindo, por isso, em dois Conteúdos Proposicionais, conforme mostra a representação semântica em (51a), e a representação morfossintática em (51b).

(51) -> eu não sei se é verdade ou se é mentira. mas, eu digo, eu posso reproduzir aquilo que os mais velhos

- hum, hum.

-> disseram. (CV95:AsMornas)

(51a) NR: (neg e $e_{i}:\left(f_{i}^{c_{i}}:\left[\left(f_{j}: s a b-\left(f_{j}\right)\right)\left(x_{i}\right)\right)_{A}\left[\left(p_{i}:-\right.\right.\right.$ se é verdade- $\left.\left(p_{i}\right)\right)\left(\vee p_{j}:-\right.$ se é mentira$\left.\left.\left.\left.\left(\mathrm{p}_{\mathrm{j}}\right)\right)\right]_{\mathrm{u}}\right]\left(\mathrm{f}_{\mathrm{i}}^{\mathrm{c}}\right)\left(\mathrm{e}_{\mathrm{i}}\right)\right)$

\footnotetext{
${ }^{15}$ Nesse córpus Doc indica documentador, e Inf., informante.
} 
(51b) NM: (Cli $:\left[\left(\mathrm{Np}_{\mathrm{i}}\right.\right.$ : -eu- $\left.\left(\mathrm{Np}_{\mathrm{i}}\right)\right)\left(\mathrm{Gw}_{\mathrm{i}}\right.$ : /nãw/ $\left.\left(\mathrm{Gw}_{\mathrm{i}}\right)\right)\left(\mathrm{Vp}_{\mathrm{i}}\right.$ : -sei- $\left.\left(\mathrm{Vp}_{\mathrm{i}}\right)\right)\left[\left(\mathrm{Cl}_{\mathrm{j}}\right.\right.$ : -se é verdade- $\left.\left(\mathrm{Cl}_{\mathrm{j}}\right)\right)\left(\mathrm{Gw}_{\mathrm{i}}\right.$ : /ow/ $\left.\left(\mathrm{Gw}_{\mathrm{i}}\right)\right)\left(\mathrm{Cl}_{\mathrm{k}}\right.$ :-se é mentira- $\left.\left.\left.\left(\mathrm{Cl}_{\mathrm{k}}\right)\right)\right]\left(\mathrm{Cl}_{\mathrm{i}}\right)\right)$

Em (52), por outro lado, Londres e qualquer parte são argumentos Locative (Alativo) da propriedade de dois lugares $i r$. Pode-se também multiplicar argumentos de nomes, com função Referência, como mostram dos civilizados e (dos) assimilados em (53). As representações semânticas das duas ocorrências encontram-se em (52a) e (53a), e as morfossintáticas, em (52b) e $(53 b)$.

(52) sim, sem emprego fixo, é. ele diz se conseguir ali está bem, senão vai, vai para Londres. vai para Londres ou qualquer parte. vai arriscar (GO:VidaFamiliar)

(52a) NR: $\quad\left(\mathrm{f}_{\mathrm{i}}^{\mathrm{c}}\right.$ : $\left[\left(\mathrm{f}_{\mathrm{i}}\right.\right.$ : ir $\left.\left.\left.\left(\mathrm{f}_{\mathrm{i}}\right)\right)\left(\mathrm{x}_{\mathrm{i}}\right)_{\mathrm{A}}\left(1 \mathrm{l}_{\mathrm{i}}\right)_{\mathrm{L}}\left(\mathrm{V}\left(1 \mathrm{l}_{\mathrm{j}}\right)\right)_{\mathrm{L}}\right]\left(\mathrm{f}_{\mathrm{i}}^{\mathrm{c}}\right)\right)$

(52b) NM: $\left(\mathrm{Cl}_{\mathrm{i}}:\left[\left(\mathrm{Vp}_{\mathrm{i}}:-\mathrm{vai}-\left(\mathrm{Vp}_{\mathrm{i}}\right)\right)\left(\mathrm{Adp}_{\mathrm{i}}\right.\right.\right.$ : $\left[\left(\mathrm{Gw}_{\mathrm{i}}:\right.\right.$ para $\left.\left(\mathrm{Gw}_{\mathrm{i}}\right)\right)\left(\mathrm{Np}_{\mathrm{i}}\right.$ : Londres $\left.\mathrm{N}_{\mathrm{N}}\left(\mathrm{Np}_{\mathrm{i}}\right)\right)\left(\mathrm{Gw}_{\mathrm{j}}\right.$ : /ow/ $\left.\left(\mathrm{Gw}_{\mathrm{j}}\right)\right)\left(\mathrm{Np}_{\mathrm{j}}:\right.$-qualquer parte- $\left.\left.\left.\left.\left.\left(\mathrm{Np}_{\mathrm{j}}\right)\right)\right]\left(\mathrm{Adp}_{\mathrm{i}}\right)\right)\right]\left(\mathrm{Cl}_{\mathrm{i}}\right)\right)$

(53) a questão dos, entre aspas, civilizados, ou entre aspas, assimilados... (AN97:Ensino Angola)

(53a) NR: $\quad\left(\mathrm{p}_{\mathrm{i}}\right.$ : $\left[\left(\mathrm{f}_{\mathrm{i}}\right.\right.$ : questão $\left.\left(\mathrm{f}_{\mathrm{i}}\right)\right)\left[\left(\mathrm{m} \mathrm{x} \mathrm{x}_{\mathrm{i}}:\left(\mathrm{f}_{\mathrm{j}}\right.\right.\right.$ : civilizado $\left.\left.\left(\mathrm{f}_{\mathrm{j}}\right)\right)\left(\mathrm{x}_{\mathrm{i}}\right)\right)\left(\mathrm{V} \mathrm{m} \mathrm{x}_{\mathrm{j}}:\left(\mathrm{f}_{\mathrm{k}}\right.\right.$ : assimilado $\left.\left(\mathrm{f}_{\mathrm{k}}\right)\right)$ $\left.\left.\left.\left.\left(\mathrm{x}_{\mathrm{j}}\right)\right)\right]_{\mathrm{Ref}}\right)\left(\mathrm{p}_{\mathrm{i}}\right)\right)$

(53b) NM: (Np $\mathrm{i}:\left[\left(\mathrm{Np}_{\mathrm{j}}:-\mathrm{a}\right.\right.$ questão- $\left.\left(\mathrm{Np}_{\mathrm{j}}\right)\right)\left(\mathrm{Adp}_{\mathrm{i}}\right.$ : - dos civilizados- $\left.\left(\mathrm{Adp}_{\mathrm{i}}\right)\right)\left(\mathrm{Gw}_{\mathrm{j}}\right.$ : /ow/ $\left.\left(\mathrm{Gw}_{\mathrm{j}}\right)\right)\left(\mathrm{Aw} \mathrm{w}_{\mathrm{j}}\right.$ : assimilados $\left.\left.\left.\left(\mathrm{Aw}_{\mathrm{j}}\right)\right)\right]\left(\mathrm{Np}_{\mathrm{i}}\right)\right)$

No Nível Representacional, a posição de predicados também pode ser multiplicada, conforme exemplifica a ocorrência (54). Já (55) ilustra um caso de duplicação de modificador de Estado de Coisas.

(54) -> são vinte, em que a língua franca é o tétum.

- hum, hum.

-> por exemplo, só no meu caso, na, na minha terra, um posto com... uma superfície um pouco superior a Macau aí... vinte vezes, fala quatro línguas, ou quatro dialectos - hum, hum.

-> para uma população de dez mil, falam quatro dialetos, mas todos eles compreendem, ouvem ou compreendem tétum, portanto, tétum é a língua franca para toda a ilha (TL99: IdentidadePovo)

(54a) NR: $\quad\left(\mathrm{e}_{\mathrm{i}}:\left(\mathrm{f}_{\mathrm{i}}\right.\right.$ : [( $\mathrm{f}_{\mathrm{i}}$ : ouv- $\left.\left(\mathrm{f}_{\mathrm{i}}\right)\right)\left(\mathrm{V} \mathrm{f}_{\mathrm{j}}\right.$ : compreend- $\left.\left.\left(\mathrm{f}_{\mathrm{j}}\right)\right)\right]\left(\mathrm{x}_{\mathrm{i}}-\text { todos eles- }\left(\mathrm{x}_{\mathrm{i}}\right)\right)_{\mathrm{A}}\left(\mathrm{x}_{\mathrm{j}}\right.$ : tétum $\left.\left.\left.\left(\mathrm{x}_{\mathrm{j}}\right) \mathrm{U}\right)\left(\mathrm{f}_{\mathrm{i}}^{\mathrm{i}}\right)\right)\left(\mathrm{e}_{\mathrm{i}}\right)\right)$

(54b) NM: (Cli : $\left(\mathrm{Np}_{\mathrm{i}}:-\right.$ todos eles- $\left.\left(\mathrm{Np}_{\mathrm{i}}\right)\right)\left[\left(\mathrm{Vp}_{\mathrm{i}}:\left(\mathrm{Vw}_{\mathrm{i}}-\right.\right.\right.$ ouvem- $\left.\left.\left(\mathrm{Vw}_{\mathrm{i}}\right)\right)\left(\mathrm{Vp}_{\mathrm{i}}\right)\right)\left(\mathrm{Gw}_{\mathrm{i}}:\right.$ /ow/ $\left.\left(\mathrm{Gw}_{\mathrm{i}}\right)\right)\left(\mathrm{Vp}_{\mathrm{j}}:\left(\mathrm{Vw}_{\mathrm{j}}:-\right.\right.$ compreendem- $\left.\left.\left.\left(\mathrm{Vw}_{\mathrm{j}}\right)\right)\left(\mathrm{Vp}_{\mathrm{j}}\right)\right)\right]\left(\mathrm{Np}_{\mathrm{j}}:\left(\mathrm{Nw}_{\mathrm{i}}:\right.\right.$ tétum $\left.\left.\left.\left(\mathrm{Nw}_{\mathrm{i}}\right)\right)\left(\mathrm{Np}_{\mathrm{j}}\right)\right)\right]$ $\left.\left(\mathrm{Cl}_{\mathrm{i}}\right)\right)$

(55) enfeita-se com o resto do ananás, como se quiser, com as rodelas partidas em meialua, é como eu faço, ou em bocadinhos, como se quiser (PT70:Bavaroise)

(55a) NR: ( $\mathrm{e}_{\mathrm{i}}$ : - enfeita-se com o resto do ananás- $\left.\left(\mathrm{e}_{\mathrm{i}}\right)\right)$ : [( $\mathrm{x}_{\mathrm{i}}$ : - com as rodelas partidas em meia-lua- $\left.\left.\left.\left(\mathrm{x}_{\mathrm{i}}\right)\right)_{\text {Manner }}\left(\mathrm{V} \mathrm{q}_{\mathrm{i}}:-\mathrm{em} \text { bocadinhos- }\left(\mathrm{q}_{\mathrm{i}}\right)\right)_{\text {Manner }}\right]\left(\mathrm{e}_{\mathrm{i}}\right)\right)$

(55b) NM: (Cli: -enfeita-se com o resto do ananás- [(Adp $\mathrm{Ad}_{\mathrm{i}}$ ( $\left(\mathrm{Gw}_{\mathrm{i}}\right.$ : com $\left.\left(\mathrm{Gw}_{\mathrm{i}}\right)\right)\left(\mathrm{Np}_{\mathrm{i}}\right.$ : -as rodelas partidas- $\left.\left.\left(\mathrm{Np}_{\mathrm{i}}\right)\right)\left(\mathrm{Adp}_{\mathrm{i}}\right)\right)\left(\mathrm{Gw}_{\mathrm{j}}\right.$ : /ow/ $\left.\left(\mathrm{Gw}_{\mathrm{j}}\right)\right)\left(\mathrm{Adp}_{\mathrm{j}}\right.$ : $\left(\mathrm{Gw}_{\mathrm{l}}\right.$ : em $\left.\left(\mathrm{Gw}_{\mathrm{l}}\right)\right)\left(\mathrm{Np}_{\mathrm{j}}\right.$ : $\left(\mathrm{Nw}_{\mathrm{i}}-\right.$ bocadinhos- $\left.\left.\left.\left.\left.\left(\mathrm{Nw}_{\mathrm{i}}\right)\right)\left(\mathrm{Np}_{\mathrm{j}}\right)\right)\left(\mathrm{Adp}_{\mathrm{j}}\right)\right)\right]\left(\mathrm{Cl}_{\mathrm{i}}\right)\right)$ 
A multiplicação de argumentos ou modificadores no Nível Representacional, aciona, no Nível Morfossintático, o processo de Empilhamento, que se dá nos limites da Oração, como mostram as representações morfossintáticas em (52b), (54b), (55b) ou mesmo na camada do sintagma, conforme se verifica em (53b).

Para Sweetser (1990: 93), ou normalmente carrega consigo uma expectativa de que apenas uma das opções expressas será a opção correta. Isso explica o fato de que, nos dados analisados, a junção alternativa se mostra apropriada para situações em que o Falante instrui o Ouvinte a lhe dar a informação correta, já que, dentre as opções apresentadas, supõe que apenas uma é a adequada. Em outras palavras, é comum o uso de ou em Atos Discursivos com ilocução interrogativa, conforme ilustram (56) e (49), repetida aqui em (57), em que ou coordena dois Atos Discursivos Interrogativos, conforme representado respectivamente em (56a) e (57a).

(56) eh, irão pagar de que maneira? não pensa numa reconciliação, ou pensa retaliar pela mesma moeda? (Ang97:JovemGaspar)

(56a) NI: $\quad\left(\mathrm{A}_{\mathrm{I}}\right.$ : $\left[\left(\mathrm{F}_{\mathrm{I}}\right.\right.$ : INTER $\left.\left(\mathrm{F}_{\mathrm{I}}\right)\right)\left(\mathrm{P}_{\mathrm{I}}\right)_{\mathrm{S}}\left(\mathrm{P}_{\mathrm{J}}\right)_{\mathrm{A}}\left(\mathrm{C}_{\mathrm{I}}\right.$ : -não pensa em uma reconciliação- $\left.\left.\left(\mathrm{C}_{\mathrm{I}}\right)\right)\right]$ $\left.\left(\mathrm{A}_{\mathrm{I}}\right)\right)\left(\mathrm{A}_{\mathrm{J}}:\left[\left(\mathrm{F}_{\mathrm{J}}\right.\right.\right.$ : INTER $\left.\left(\mathrm{F}_{\mathrm{J}}\right)\right)\left(\mathrm{P}_{\mathrm{I}}\right)_{\mathrm{S}}\left(\mathrm{P}_{\mathrm{J}}\right)_{\mathrm{A}}\left(\mathrm{C}_{\mathrm{J}}\right.$ : -pensa retaliar pela mesma moeda- $\left.\left.\left(\mathrm{C}_{\mathrm{J}}\right)\right)\right]$ $\left.\left.\left(\mathrm{A}_{\mathrm{J}}\right)\right)\right]$

(57) Doc.: tem algum outro que cê sabe?

Inf.: ...uhm::...eu-a-cho-que-nã::o... que tipo de jogo você fala assim jogos assim ou jogo de por exemplo bola queima::da (AC-006)

(57a) NI: (A: $\left[\left(\mathrm{F}_{\mathrm{I}}\right.\right.$ : INTER $\left.\left.\left.\left(\mathrm{F}_{\mathrm{I}}\right)\right)\left(\mathrm{P}_{\mathrm{I}}\right)_{\mathrm{S}}\left(\mathrm{P}_{\mathrm{J}}\right)_{\mathrm{A}}\left(\mathrm{C}_{\mathrm{I}}:\left(\mathrm{R}_{\mathrm{I}}-\mathrm{jog} \operatorname{jos} \operatorname{assim}-\left(\mathrm{R}_{\mathrm{I}}\right)\right)\left(\mathrm{C}_{\mathrm{I}}\right)\right)\right]\left(\mathrm{A}_{\mathrm{I}}\right)\right)\left(\mathrm{A}_{\mathrm{J}}\right.$ : $\left[\left(\mathrm{F}_{\mathrm{J}}\right.\right.$ : INTER $\left.\left(\mathrm{F}_{\mathrm{J}}\right)\right)\left(\mathrm{P}_{\mathrm{I}}\right)_{\mathrm{S}}\left(\mathrm{P}_{\mathrm{J}}\right)_{\mathrm{A}}\left(\mathrm{C}_{\mathrm{J}}:\left(\mathrm{R}_{\mathrm{J}}-\right.\right.$ jogo de por exemplo bola queimada- $\left.\left.\left.\left(\mathrm{R}_{\mathrm{J}}\right)\right)\left(\mathrm{C}_{\mathrm{J}}\right)\right)\right]$ $\left.\left(\mathrm{A}_{\mathrm{J}}\right)\right)$

A ocorrência (58) exemplifica um caso tradicionalmente denominado interrogativa indireta, já que o Ato Discursivo eu não sei se é verdade ou se é mentira tem ilocução Declarativa, mas a palavra gramatical se introduzindo os dois Conteúdos Proposicionais indica tratar-se de duas opções em que apenas uma é a correta.

(58) -> eu não sei se é verdade ou se é mentira. mas, eu digo, eu posso reproduzir aquilo que os mais velhos

- hum, hum.

-> disseram. (CV95:AsMornas)

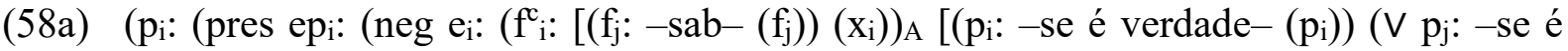
mentira- $\left.\left.\left.\left(\mathrm{p}_{\mathrm{j}}\right)\right]_{\mathrm{u}}\right]\left(\mathrm{f}_{\mathrm{i}}\right)\left(\mathrm{e}_{\mathrm{i}}\right)\right)$

(58b) $\left(\mathrm{Cl}_{\mathrm{i}}:\left[\left(\mathrm{Np}_{\mathrm{i}}:-\mathrm{eu}-\left(\mathrm{Np}_{\mathrm{i}}\right)\right)\left(\mathrm{Gw}_{\mathrm{i}}: /\right.\right.\right.$ naw/ $\left.\left(\mathrm{Gw}_{\mathrm{i}}\right)\right)\left(\mathrm{Vp}_{\mathrm{i}}:-\right.$ sei- $\left.\left(\mathrm{Vp}_{\mathrm{i}}\right)\right)\left[\left(\mathrm{Cl}_{\mathrm{j}}\right.\right.$ :-se é verdade- $\left.\left(\mathrm{Cl}_{\mathrm{j}}\right)\right)$ $\left(\mathrm{Gw}_{\mathrm{i}}\right.$ : /ow/ $\left.\left(\mathrm{Gw}_{\mathrm{i}}\right)\right)\left(\mathrm{Cl}_{\mathrm{k}}\right.$ : - se é mentira- $\left.\left.\left.\left(\mathrm{Cl}_{\mathrm{k}}\right)\right)\right]\left(\mathrm{Cl}_{\mathrm{i}}\right)\right)$

A alternativa, assim como a aditiva, vem do Nível Representacional. O sentido literal de uma relação alternativa é sempre exclusivo, pois implica que o falante desconhece qual das opções combinadas venha a ser a verdadeira, ao mesmo tempo em que assume que as opções oferecidas não são simultaneamente corretas. As unidades combinadas no Nível Representacional devem ser equivalentes, ou seja, pertencer à mesma camada deste nível. 


\subsection{Adversativa}

Conforme Hengeveld/Mackenzie (2008: 52), Atos Discursivos podem ser combinados numa relação de dependência, quando o falante atribui estatutos comunicativos diferentes a cada um deles. Nesse caso, há sempre um Ato Discursivo Nuclear, com maior peso comunicativo, e um Ato Discursivo Subsidiário, que terá uma função retórica. É o que acontece, em (59), entre o Ato Nuclear The work was fairly easy e o Ato Subsidiário although it took me longer than expected, com a função retórica Concessão. A possibilidade de se inserir o predicado performativo to concede ('admitir') indica que a concessão ocorre no Nível Interpessoal entre Atos Discursivos. A Concessão, como função retórica, é marcada no Ato Discursivo Subsidiário por conc.

(59) The work was fairly easy, although (I concede that) it took me longer than expected. (Hengeveld/Mackenzie 2008: 54)

O trabalho foi fácil, embora (eu admito) levou mais tempo do que o esperado. (Tradução nossa).

(59a) $\left(\mathrm{M}_{\mathrm{I}}\right.$ : $\left[\left(\mathrm{A}_{\mathrm{I}}\right.\right.$ : - the work was fairly easy- $\left.\left(\mathrm{A}_{\mathrm{I}}\right)\right)\left(\mathrm{A}_{\mathrm{J}}\right.$ : - it took me longer than expected$\left.\left.\left.\left(\mathrm{A}_{\mathrm{J}}\right)\right)_{\mathrm{Conc}}\right]\left(\mathrm{M}_{\mathrm{I}}\right)\right)$

A Concessão interpessoal pode também ser indicada por but. Nesse caso, o Ato Subsidiário permite a adição de um modificador como admittedly ('reconhecidamente', 'de fato', 'sim'), que cria a expectativa de que o ato seguinte é o nuclear, como mostra (60), cuja representação se encontra em (60a).

(60) The work (admittedly) took longer than expected, but it was easy. (Hengeveld/Mackenzie 2008: 55).

O trabalho (eu admito) levou mais tempo que o esperado, mas foi fácil. (Tradução nossa).

(60a) $\left(\mathrm{M}_{\mathrm{I}}\right.$ : $\left[\left(\mathrm{A}_{\mathrm{I}} \text { : - the work took longer than expected- }\left(\mathrm{A}_{\mathrm{I}}\right)\right)_{\text {Conc }}\left(\mathrm{A}_{\mathrm{J}}:-i \mathrm{t}\right.\right.$ was easy- $\left.\left.\left.\left(\mathrm{A}_{\mathrm{J}}\right)\right)\right]\left(\mathrm{M}_{\mathrm{I}}\right)\right)$

Observam os autores (Hengeveld/Mackenzie 2008: 54-55) que é muito importante a ordem em que os Atos Discursivos são expressos dentro do Movimento, já que a realização de funções retóricas por morfemas gramaticais depende da posição do Ato discursivo Subsidiário relativamente ao Ato Nuclear. Assim, o uso de although ou but para indicar a Concessão interpessoal está condicionado à posição antes ou depois do Ato Subsidiário ao Nuclear, conforme mostra respectivamente a representação do Nível Morfossintático em (59b) e (60b).

(59b) $\left(\mathrm{Le}_{\mathrm{i}}:\left[\left(\mathrm{Cl}_{\mathrm{i}}\right.\right.\right.$ : -the work was fairly easy- $\left.\left(\mathrm{Cl}_{\mathrm{i}}\right)\right)\left(\mathrm{Cl}_{\mathrm{j}}\right.$ : $\left[\left(\mathrm{Gw}_{\mathrm{i}}\right.\right.$ : although $\left.\left(\mathrm{Gw}_{\mathrm{i}}\right)\right)-\mathrm{it}$ took me longer than expected-] $\left.\left.\left.\left(\mathrm{Cl}_{\mathrm{j}}\right)\right)\right]\left(\mathrm{Le}_{\mathrm{i}}\right)\right)$

(60b) (Le $\mathrm{Le}_{\mathrm{i}}$ : $\left[\left(\mathrm{Cl}_{\mathrm{i}}\right.\right.$ : -the work took longer than expected- $\left.\left(\mathrm{Cl}_{\mathrm{i}}\right)\right)\left(\mathrm{Gw}_{\mathrm{i}}\right.$ : but $\left.\left(\mathrm{Gw}_{\mathrm{i}}\right)\right)\left(\mathrm{Cl}_{\mathrm{j}}-\mathrm{it}\right.$ was easy- $\left.\left.\left.\left(\mathrm{Cl}_{\mathrm{j}}\right)\right)\right]\left(\mathrm{Le}_{\mathrm{i}}\right)\right)$

Propomos, neste estudo, que mas, além da concessividade no Nível Interpessoal, indica adição no Nível Representacional, quer dizer, a palavra mas expressa a combinação NI: Conc + NR: Adição.

Sweetser (1990: 103), tomando o exemplo em (61), observa que, para se interpretar que João é rico e Bill é pobre como unidades contrastivas ou incompatíveis, há a necessidade de se fazer inferências, já que não pode haver discordância ou contraste fora do conceito mental do falante. 
Se há a necessidade de inferências, então, o nível do conteúdo não é o ideal para que o contraste se estabeleça. Desse modo, segundo a autora, não existe um uso de mas no domínio de conteúdo, mas apenas no domínio epistêmico e do ato de fala.

(61) John is rich but Bill is poor. (Sweetser 1990: 103)

'O João é rico, mas Bill é pobre.'

Longhin/Pezatti/Novaes-Marques (2019: 63), por seu turno, observam que o coordenador adversativo introduz o segundo membro da construção, o que comporta a informação argumentativamente mais decisiva, que se pode conformar a uma refutação, a uma correção, a uma ressalva, a uma diferença, a uma surpresa ou a uma contra-argumentação, frente ao conteúdo do primeiro membro. Afirmam as autoras que

Embora o latim clássico dispusesse de um elenco considerável de juntores para a sinalização da adversidade (sed, uerum, at, atqui, immo, autem, uero, tamen, quidem, nihilominus), sabemos que o português nada herdou desse sistema (cf. Maurer Jr. 1959; Câmara Jr. 1976). Por outro lado, nas variedades vulgares do latim, tornou-se especializado o emprego de magis, advérbio comparativo de superioridade para marcação de adversidade, do que resultou a emergência de mais/mas, a conjunção adversativa mais antiga e a mais prototípica do português (cf. Maurer Jr. 1959; Barreto 1999).

(ibd.: 64)

Como se vê, a propriedade de soma/adição $(\Lambda)$ de mas em português remonta sua origem adverbial de comparação de superioridade, como em mais velho, mais triste, própria do Nível Representacional.

Consideremos a ocorrência (62):

- não, mas eu digo, estava em ti[...], Macau, em

-> sim, eu estive em Timor.

- Timor, nessa altura.

-> estive em Timor naquela altura, mas eu não participei. (TL99:Timor)

Em (62), não há dúvida de que estar em Timor naquele momento possibilitaria a participação no massacre de Santa Cruz. O Falante, no entanto, retomando a informação já disponível para o Ouvinte, admite que esteve em Timor naquele momento, e acrescenta a informação contrastiva, argumentativamente mais decisiva, que é a não participação no evento, conforme a paráfrase em (62a-b). Essa estratégia caracteriza a função retórica Concessão, marcada por Conc, no Ato Discursivo subsidiário que antecede o Ato nuclear, como se representa em (62c).

(62a) estive (eu admito) em Timor naquela altura, mas eu (afirmo) não participei.

(62b) estive ( $\operatorname{sim}$ ) em Timor naquela altura, mas eu (afirmo) não participei.

(62c) NI: $\quad\left(\mathrm{M}_{\mathrm{I}}\right.$ : $\left[\left(\mathrm{A}_{\mathrm{I}}\right.\right.$ : - estive em Timor naquela altura- $\left.\left(\mathrm{A}_{\mathrm{I}}\right)_{\mathrm{Conc}}\right)\left(\mathrm{A}_{\mathrm{J}}\right.$ : -não participei- $\left.\left.\left(\mathrm{A}_{\mathrm{J}}\right)\right)\right]$ $\left.\left(\mathrm{M}_{\mathrm{I}}\right)\right)$

É nítida, entretanto, a necessidade do acréscimo do conteúdo veiculado pelo Conteúdo Comunicativo do Ato Discursivo nuclear, que se mostra muito importante para o que o Falante deseja significar. A origem adverbial de mas dá a ele essa propriedade, a de adição. Assim a contraposição expressa por mas indica ao mesmo tempo concessividade no Nível Interpessoal e adição no Nível Representacional, quer dizer, a palavra mas expressa a combinação 
NI: Conc + NR: Adição $(\wedge) .{ }^{16}$ Desse modo, a ocorrência (62) tem as seguintes representações nos dois níveis de formulação, conforme mostra (62d):

(62d) NI: $\quad\left(\mathrm{M}_{\mathrm{I}}\right.$ : $\left[\left(\mathrm{A}_{\mathrm{I}}\right.\right.$ : - estive em Timor naquela altura- $\left(\mathrm{A}_{\mathrm{I}}\right)$ Conc $)\left(\mathrm{A}_{\mathrm{J}}\right.$ : -não participei- $\left.\left.\left(\mathrm{A}_{\mathrm{J}}\right)\right)\right]$ $\left.\left(\mathrm{M}_{\mathrm{I}}\right)\right)$

NR: $\quad\left(p_{i}\right.$ :-estive em Timor naquela altura $\left.-\left(p_{i}\right)\right)\left(\wedge p_{j}:-\right.$ eu não participei- $\left.\left(p_{j}\right)\right)$

Essas duas propriedades, concessividade (Conc) e adição $(\Lambda)$, desencadeiam, no Nível Morfossintático, a inserção de mas, e não de embora, conforme a equação em (62e), e representação em (62f):

(62e) NI: $\quad\left(\ldots\left(\mathrm{A}_{1}\right)_{\text {Conc } \ldots)} \ldots\right)+\mathrm{NR}:\left(\mathrm{p}_{1}\right) \wedge\left(\mathrm{p}_{2}\right)=\mathrm{NM}:\left(\mathrm{Gw}_{1}:\right.$ mas $\left.\left(\mathrm{Gw}_{1}\right)\right)$

(62f) NM: (Le $\mathrm{i}$ : $\left[\left(\mathrm{Cl}_{\mathrm{i}}\right.\right.$ : - estive em Timor naquela altura- $\left.\left(\mathrm{Cl}_{\mathrm{i}}\right)\right)\left(\mathrm{Gw}_{\mathrm{i}}\right.$ : mas $\left.\left(\mathrm{Gw}_{\mathrm{i}}\right)\right)\left(\mathrm{Cl}_{\mathrm{j}}-\mathrm{eu}\right.$ não participei- $\left.\left.\left.\left(\mathrm{Cl}_{\mathrm{j}}\right)\right)\right]\left(\mathrm{Le}_{\mathrm{i}}\right)\right)$

A ocorrência (63) também exemplifica um caso de combinação de dois Atos Discursivos, em que o Conteúdo Comunicativo do primeiro, considerado consensual, ancora o Conteúdo Comunicativo do segundo Ato Discursivo, o nuclear.

eles (eu admito) dizem cultura mas não sabem bem (eu afirmo) a definição dessa palavra "cultura". (GB95:JuventudeGuineense)

Uma propriedade da função retórica Concessão é admitir paráfrases com a conjunção concorrente, ou seja, mas pode ser substituída por embora e embora, por mas. Obviamente são necessárias adaptações na ordenação das orações e, por vezes, na forma verbal, para preservar a função retórica aplicada ao Ato Subsidiário, conforme mostram (63a) e (64a).

(63a) não sabem bem a, a definição dessa palavra cultura, embora digam cultura

(64) nas cartas portuguesas foi inserida uma escala de latitudes, embora as cartas não estivessem preparadas para isso. foi abusivamente, podemos dizer, inserida uma escala de latitudes (PT89:Cartografia Portuguesa)

(64a) as cartas portuguesas não estavam preparadas, mas foi inserida uma escala de latitudes nessas cartas. foi abusivamente, podemos dizer, inserida uma escala de latitudes.

Há casos, entretanto, como (65), em que considerar a existência de um Ato Discursivo subsidiário com a função Concessão (na infância foram roupas iguais) e um Ato Discursivo nuclear (mas cor diferente) não parece adequado, visto que é possível dizer na infância (eu admito) foram roupas iguais, porém parece estranho, nesse contexto discursivo, dizer mas (afirmo) cor diferente.

(65) - e quando vocês eram pequenas, vocês se vestiam iguais, tudo?

-> na maioria das vezes era, eram roupas iguais mas não assim mesma cor, tal, não é?, tudo dois de paus assim, não é?, nunca gostámos disso, ai menina, sempre foi assim igual mas cores diferentes, não é?, mas mesmo estilo de roupa, tudo. conforme a gente foi crescendo, a partir de, de doze anos, onze anos, não é?, aí, o estilo sempre foi igual, mas roupas assim nunca iguais, sabe?, sempre a gente quis comprar roupa diferente, tudo. aí, quando e[...], ela escolhia a roupa que eu gostava na minha frente, eu ficava

\footnotetext{
16 Essa dupla propriedade se reflete na correlação "não só... mas também”, tradicionalmente denominada "aditiva", nas gramáticas de referência do português.
} 
brava, porque eu queria aquela e eu não podia ter aquela que ia ser igual, eu tinha que escolher outra para não ficar igual a ela, não é?, fo[...], foi bem por aí, assim na, na infância, foi ro[...], foram roupas iguais mas cor diferente, e ainda bem que minha mãe teve pelo menos a ideia de mudar a cor, não é, e depois, quando a gente começou a crescer um pouquinho a gente foi... mudando. (BR95: MuitoIguaisDiferentes)

Em (66) - sentado, mas adormecido -, também é estranho considerar que tanto sentado quanto adormecido constituem Atos Discursivos, sendo o primeiro subsidiário e o segundo nuclear.

(66) -> julgo que já tinha quatro anos, eh, aconteceu-me algo de muito engraçado [...]

-> estando de fora da casa. fiquei ali, a ver... o, o engraçado para mim era ver as águas a cair daquele capim para o chão!

- pois.

-> fiquei ali durante... todo o tempo que pude, a assistir àquele espectáculo de água que caía, depois acabei por apanhar sono, e eu estava um pouco deslocado, eh, em relação à porta. portanto, como aquilo é redondo, a minha mãe quando chegou não foi capaz de me localizar! é engraçado que ela aflita

- ih!

-> eh, nunca se lembrou de dar a volta à casa.

- hum, hum.

-> teve que me procurar na vizinhança, que também não podia sega[...], ah, seguir a pegada, porque, como choveu, todas elas desapareceram!

$-[\ldots]$

-> eh, eu continuava ali a dormir, eh, e ela também aflita, só muito mais tarde, quando ela já estava a pensar que devia fazer uma distância de quase dois ou três quilómetros, para casa dos meus avós maternos para ver se eu teria ido para lá

- hum.

-> é que, quando ia a sair, em vez de utilizar o caminho que dava saída, portanto, de casa, eh, quis cortar. portanto, então viu que eu que estava ali, sentado, mas adormecido. eh, é um facto que eu nunca mais esqueci na minha vida (MO86: Chuva)

As duas últimas ocorrências mostram a crença do falante de que roupa igual tende a ter a mesma cor, em (65), e que sentado exige estar alerta, em (66), ou seja, implica tratar-se de domínio epistêmico, mas não do ato de fala, portanto, não constituem Atos Discursivos.

Construções como roupas iguais mas cor diferente e sentado, mas adormecido sugerem a existência de adversidade entre Subatos que compõem um único Conteúdo Comunicativo. Não se trata, portanto, de função retórica entre Atos Discursivos, uma vez que não se relaciona aos modos pelos quais o Falante ordena os componentes de um discurso para influenciar o Ouvinte a aceitar seus propósitos comunicativos. Trata-se, na verdade, do modo como o Falante modela as suas mensagens em relação às expectativas que tem do estado mental do Ouvinte, determinando as partes de uma unidade linguística que serão apresentadas como particularmente salientes, as que serão escolhidas como ponto de partida do Falante e as que serão consideradas compartilhadas pelo Falante e pelo Ouvinte. Trata-se, portanto, de função pragmática, que se aplica ao Conteúdo Comunicativo ou a seus componentes. Hengeveld/ Mackenzie (2008: 91-99) distinguem três funções pragmáticas, Tópico, Foco e Contraste, que 
são linguisticamente marcadas, e têm como contraparte, respectivamente, o fundo (background), o comentário (comment) e a sobreposição (overlap), que raramente são marcados nas línguas. Por ora, interessa-nos a função pragmática Contraste.

Bolinger (1961: 83) define contraste como o fenômeno pelo qual dois ou mais itens são contrabalançados, indicando-se a preferência por um deles ou por vários membros do grupo. Ressalta, porém, que só há contrastive accent quando o número de candidatos a ocupar a posição potencialmente contrastiva é limitado. Chafe (1976), por seu turno, considera que o fenômeno da contrastividade envolve três fatores: o conhecimento pressuposto (background knowledge); o número, geralmente limitado, de candidatos possíveis para exercer o papel em questão; e a asserção que contrasta o candidato correto com outros possíveis, quer dizer, "eu acredito que você acredita que algo aconteceu, que você tem um conjunto limitado de candidatos na mente e eu digo a você que esse alguém é alguém específico e não outro qualquer" (Chafe 1976: 34-35). Já Taglicht (1984) entende que um elemento é contrastivo quando apresentado como um de um par de opostos. Para ele, a oposição é um conceito pragmáticocontextual, que pode ser representada por termos semanticamente opostos (ex.: frio vs. quente, agradável vs. chato etc.) ou por estruturas sintaticamente paralelas (ex.: João é agradável e Paulo, um chato). O contraste também pode ser caracterizado como explícito (ambos os membros do par de opostos estão presentes no enunciado) ou implícito (apenas um elemento do par está presente). De acordo com Taglift (1984), é a forma do enunciado que transmite a implicação de que alguma coisa não dita teria contido o outro membro.

Dik (1997a: 331-334), por sua vez, considera contraste um tipo de foco, a que denomina Foco Contrastivo. Nesses casos, a informação focalizada nem sempre é totalmente nova, mas é colocada em foco em virtude de algum contraste implícito ou explícito com alguma parte da informação. Quando os elementos focalizados são expressos na estrutura sintática com a mesma função, o contraste é explícito e denominado Foco Paralelo. Nos outros tipos de Foco Contrastivo, a informação apresentada contrasta com outra que o Falante pressupõe estar armazenada na memória do destinatário. Implica sempre uma pressuposição, sendo por isso denominado de Contrapressuposicional, que, por sua vez pode ser de Rejeição (o Falante presume que o Ouvinte tem uma parte de informação X para a qual o Falante tem não-X, por isso corrige a informação do Ouvinte, rejeitando-a); Substitutivo (o Falante pressupõe que o destinatário dispõe de uma parte incorreta de informação $X$, que deve ser substituída por uma correta informação Y); Expansivo (o Falante pressupõe que o destinatário dispõe de uma informação $\mathrm{X}$, mas que $\mathrm{X}$ não está completa, havendo uma informação $\mathrm{Y}$, importante que o destinatário conheça); Restritivo (o Falante presume que o destinatário dispõe de uma parte de informação correta e outra incorreta. Nesse caso, o Falante corrige a informação pragmática do destinatário ao restringir um conjunto de itens pressupostos àqueles que considera ter os valores para a posição envolvida); Seletivo (o Falante pressupõe que o destinatário acredita que a informação X ou Y está correta, mas não sabe qual).

Hengeveld/Mackenzie (2008: 96-99), por sua vez, consideram Contraste uma função pragmática, ao lado de Foco e Tópico. A função Contraste, para a GDF, assinala o desejo do Falante de realçar diferenças particulares entre dois ou mais Conteúdos Comunicativos ou entre um Conteúdo Comunicativo e informações contextualmente disponíveis, no cotexto ou na situação discursiva. Na verdade, a função pragmática Contraste envolve todos os tipos de Foco 
Contrastivo propostos por Dik (1997a: 331-332), com exceção do Foco Pergunta e do Foco Completivo, em que há uma lacuna de informação por parte do Falante, que se manifesta por meio do questionamento da informação lacunar, ou da apresentação de novas informações preenchendo tal lacuna, isto é, nos pares de pergunta-resposta, tanto em perguntas Q-word, quanto em perguntas Sim/Não, em que o Foco é o valor de verdade da proposição.

Segundo Pezatti (2012), a função Contraste, em português, é geralmente marcada por palavras gramaticais, que normalmente antecedem o termo contrastado. Palavras como apenas e só restringem um conjunto de itens pressupostos àquele que o Falante considera adequado, corrigindo a informação pragmática do Ouvinte, conforme (67); marcadores como também adicionam uma informação a outra pressuposta ou já mencionada, uma vez que o Falante acredita que o Ouvinte detém uma informação que não está completa, como em (68); por outro lado, sobretudo indica a crença do Falante de que o Ouvinte acredita que mais de uma informação pode ser correta, por isso seleciona a informação mais adequada, como se pode constatar em (69). Outra estratégia do Falante para contrastar duas informações é indicar ao Ouvinte que substitua uma informação incorreta pela que ele (Falante) considera a correta. É exatamente isso que expressam as construções tradicionalmente denominadas clivadas, como em (70).

(67) encontramos nos campos apenas mulheres (GB95:MulherAfricana:37)

(68) também aparece a esterilidade (GB95:Aborto:56)

(69) e isso vai-se traduzir numa primeira explosão escolar sobretudo no secundário (Ang97:EnsinoAngola:49)

(70) já não são as senhoras que se vão sentar à frente da cadei[...], com a cadeira à frente do, do palanque, já é os jovens e, e pronto (PT96:MeioPequeno:9)

Nesses casos, o Contraste se estabelece entre um Conteúdo Comunicativo e informações contextualmente disponíveis, ou seja, uma das partes contrastadas fica pressuposta. Em (67), mulheres se contrapõe a homens, que não é explicitamente expresso; em (68), infertilidade contrasta com outras consequências do aborto clandestino, anteriormente mencionadas no discurso; em (69), a informação não explícita é primário que se contrapõe a secundário. Em (70), no entanto, as duas informações contrastadas, as senhoras e os jovens, estão claramente explicitadas.

Como já aventado, propõe-se neste estudo que o uso de mas para juntar Subatos consiste na estratégia linguística de contrastar duas informações explícitas, dando maior destaque à informação precedida por mas. Dito de outro modo, mas constitui um expediente para indicar a função pragmática Contraste entre duas informações expressas. Dik (1997a: 331) denomina esse tipo de construção de Foco Paralelo, que é atribuído a constituintes em construções paralelas, como se observa em (65) e (66), repetidas aqui por conveniência em (71) e (72), em que respectivamente iguais contrasta com cor diferente e sentado com adormecido, sendo assim representadas no Nível Interpessoal.

(71) assim na, na infância, foi ro[...], foram roupas iguais mas cor diferente, (BR95: MuitoIguaisDiferentes)

NI: $\left(A_{I}:\left(C_{I}:\left[\left(R_{I}:-\right.\right.\right.\right.$ roupas- $\left.\left(R_{I}\right)\right)\left[\left(T_{I}:-\right.\right.$ iguais- $\left.\left.\left.\left.\left(T_{I}\right)\right)\left(T_{J}:- \text { cor diferente- }\left(T_{J}\right)\right)_{\text {Contr }}\right]\right]\left(C_{I}\right)\right)$ $\left.\left(\mathrm{A}_{\mathrm{I}}\right)\right)$ 
(72) então viu que eu que estava ali, sentado, mas adormecido (MO86: Chuva), NI: $\left(\mathrm{A}_{\mathrm{I}}:\left(\mathrm{C}_{\mathrm{I}}:\left[\left(\mathrm{T}_{\mathrm{I}}\right.\right.\right.\right.$ : -sentado- $\left.\left.\left.\left.\left(\mathrm{T}_{\mathrm{I}}\right)\right)\left(\mathrm{T}_{\mathrm{J}} \text { :-adormecido- }\left(\mathrm{T}_{\mathrm{J}}\right)\right)_{\text {Contr }}\right]\left(\mathrm{C}_{\mathrm{I}}\right)\right)\left(\mathrm{A}_{\mathrm{I}}\right)\right)$

As ocorrências de (73), (74) e (75) exemplificam também casos de Contraste em construções paralelas, em que bem longe da casa contrasta com dentro do território familiar em (72); formado contrasta com formado com terra dentro em (73); e treino técnico com própria da técnica em si, em (74). Uma característica dessas construções é a repetição do (ou parte do) primeiro membro contrastado, como mostra (73). Percebe-se, nesses casos, traços da incrementabilidade da fala, já que há a tentativa do falante de especificar o que acaba de dizer, de o afinar para evitar mal entendidos.

(73) agora, bem longe da casa, dessa fazenda, mas dentro ainda do, do território familiar, tem uma piscina, piscina natural (BRA72:Fazenda)

- você disse que tem uma piscina de água natural, quer dizer, a, a água vem de, de onde? -> a água vem de um rio... ela é represada num pequeno lugar. e este lugar justamente, quando os tios mandaram fazer, eles acharam que seria um lugar ideal porque alargava ligeiramente, quer dizer, o rio dava uma lá[...], um alargamento, tinha uma ligeira queda. então acharam engraçado que realmente parecia que estava formado aquilo ali, $\underline{\text { mas }}$ formado com terra dentro e mato etc., etc. (BR72:Fazenda).

(75) -> há o treino conjunto, que é

- ah, pois. [...]

-> pois, futebol. e há o treino técnico específico, que é jogadas ensaiadas, tipo livres, directos, cantos, e depois há outro treino técnico mas... de, da própria técnica em si (PT95:JogarFutebol).

Já em (76), o uso de mas é diferente dos anteriores, pois não se trata de adição de informação, mas da escolha da expressão linguística correta. Esse exemplo contém uma intervenção do falante/escritor para fornecer ao Ouvinte uma informação que ele considera importante.

(76) nas cartas portuguesas foi inserida uma escala de latitudes, embora as cartas não estivessem preparadas para isso. foi abusivamente, podemos dizer, inserida uma escala de latitudes e mais tarde alguém teve a ideia de transferir a mesma escala de latitudes para o equador, o que deu como resultado que a carta está, não expressamente, mas implicitamente, dividida em pequenas quadrículas. é uma quadrícula. e então nasceu a tal célebre carta plana-quadrada. (PT89:CartografiaPortuguesa:49).

Numa formulação representacional, poder-se-ia ter escrito "a carta está implicitamente dividida em pequenas quadrículas". Para enfatizar o implícito, o falante utiliza uma estratégia de começar por rejeitar a negação do que pretende comunicar (não expressamente mas implicitamente). Casos como (76) sugerem uma negação metalinguística, no sentido dado por Hengeveld/Mackenzie (2018: 40), no exemplo She is not unhappy, she is depressed ('Ela não está infeliz, ela está deprimida').

Em (77), por outro lado, a estratégia do político é afastar a ideia de que pudesse ter razões eleitorais para não se recandidatar e substituir a ideia de que age coerentemente e em conformidade com a constituição. Nesse caso, há primeiramente a negação e depois a correção de Conteúdos Comunicativos, ou, em outros termos, uma rejeição seguida de uma substituição (Dik 1997a: 331). 
(77) não desejo recandidatar-me. não por razões portanto eleitorais que nunca estiveram no meu espírito mas por leitura que faço da constituição e coerência. ${ }^{17}$ eu há muito tempo que digo que o presidente não deve intervir. (PT90:PoderesCE:58).

Anscombre/Ducrot (1977) propõem a existência de dois mais ('mas') em francês, considerando a distinção do alemão entre sondern e aber, em sentenças como Ich verleugnete Jesus, niet einmal, nicht zweimal, sondern/*aber driemal ('eu neguei Jesus, não uma vez, não duas, mas três vezes'), diferença também existente no espanhol entre sino e pero, ${ }^{18}$ e em italiano, entre ma e però, conforme exemplificam (77a), (77b) e (77c), que não resulta em formas diferentes em francês. Este parece ser o caso também em português: uma mesma forma para diferentes usos, como em (78) (79).

(77a) Ich will nicht wieder kandidieren, nicht aus ... ähm ... wahltaktischen Gründen, die mir überhaupt nie in den Sinn gekommen sind, sondern/*aber wegen meiner Auslegung der Verfassung und um konsequent zu handeln. ${ }^{19}$

(77b) No presentaré mi candidatura de nuevo; no por razones electorales, que nunca tuve en la cabeza, sino/*pero debido a mi lectura de la Constitución, y por ser consistente. ${ }^{20}$

(77c) Non intendo ricandidarmi. Non per ragioni elettorali che non sono mai state tra i miei pensieri ma/*però per l'interpretazione che do della costituzione e per coerenza. ${ }^{21}$

Em (78), a construção com mas sim em português assemelha-se ao sondern alemão. É possível, no entanto, ver sim como expressão de um operador de polaridade positiva, como no exemplo (79).

(78) um outro médico, ah, grego, conseguiu demonstrar que o que circula nos nossos vasos

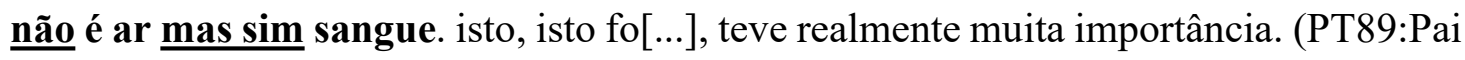
Medicina)

(79) - quanto é que calcula que vale a sua colecção?

-> bem, não sei dizer, é muito difícil. eh, nã[...], não há, neste momento não há em jo[...], não está em jogo o aspecto... monetário

$-\operatorname{sim}$.

-> mas sim o da cultura. porque agora já sei... muitas coisas sobre borboletas, que fui obrigado a col[...], comprar livros (CV95:Coleccionismo)

Como é possível notar, nas construções em (76), (77), (78) e (79), há a rejeição do primeiro membro do par por meio do operador de polaridade negativa não seguida da substituição pelo segundo membro, algumas vezes reforçada pelo operador de polaridade positiva sim. Como se vê, mas nesses casos indica também Contraste, já que contrapõe duas informações explícitas, negando a primeira e substituindo-a pela seguinte.

\footnotetext{
17 Portanto: marcador de disfluência tipicamente português ( $p^{\prime}$ tant $\left.t^{\prime}\right)$, por isso foi traduzido por ähm em alemão.

18 Sino, conjunção adversativa exclusiva, que indica oposição entre dois elementos ou entre circunstâncias incompatíveis, indicando negação total do primeiro membro.

${ }^{19}$ Agradecemos a Dirk Siepmann e John Desmond Gallagher pela sua inestimável ajuda na tradução deste exemplo.

${ }^{20}$ Agradecemos a Laura Alba-Juez pela sua inestimável ajuda na tradução deste exemplo.

${ }^{21}$ Agradecemos a Riccardo Giomi pela sua inestimável ajuda na tradução deste exemplo.
} 
Os dados mostram que mas, quando combina Subatos, serve à estratégia de ressaltar uma informação contrastando-a com outra explícita. É o mecanismo usado para indicar a função pragmática Contraste, estando expressas as informações contrastadas, podendo, no entanto, indicar adição, conforme mostram (65) e (66), repetidas por conveniência em (80) e (81), ou a combinação de rejeição e substituição, como em (82), e (83), que repete (78).

(80) assim na, na infância, foi ro[...], foram roupas iguais mas cor diferente, (BR95: MuitoIguaisDiferentes)

(81) -> é que, quando ia a sair, em vez de utilizar o caminho que dava saída, portanto, de casa, eh, quis cortar. portanto, então viu que eu que estava ali, sentado, mas adormecido. eh, é um facto que eu nunca mais esqueci na minha vida (MO86: Chuva)

(82) -> é que eu não conheço o norte. eu tenho maior vontade!

- os pais pernambucanos, mas você nunca foi?

-> nunca fui a Pernambuco. não, não $\mathrm{s}[\ldots]$, meus pais não, mas meus avós.

- é os avós. (BR80:ArteUrbana)

(83) um outro médico, ah, grego, conseguiu demonstrar que o que circula nos nossos vasos não é ar mas sim sangue. isto, isto fo[...], teve realmente muita importância. (PT89:Pai Medicina)

Não há restrição com relação aos dois Subatos contrastados, que podem ser Atributivos, como em (84), ou Referenciais, como em (85), que retoma (82), respectivamente representadas nos três níveis em $(84 a, b, c)$ e $(85 a, b, c)$.

(84) então viu que eu que estava ali, sentado, mas adormecido. (MO86: Chuva),

(84a) NI: $\quad\left(\mathrm{A}_{\mathrm{I}}:\left(\mathrm{C}_{\mathrm{I}}\right.\right.$ : [( $\mathrm{T}_{\mathrm{I}}$ : - sentado- $\left.\left.\left.\left.\left(\mathrm{T}_{\mathrm{I}}\right)\right)\left(\mathrm{T}_{\mathrm{J}} \text { :-adormecido- }\left(\mathrm{T}_{\mathrm{J}}\right)\right)_{\text {Contr }}\right]\left(\mathrm{C}_{\mathrm{I}}\right)\right)\left(\mathrm{A}_{\mathrm{I}}\right)\right)$

(84b) NR: $\quad\left(\mathrm{e}_{\mathrm{i}}:\left[\left(\mathrm{f}_{\mathrm{i}}-\right.\right.\right.$ sentado- $\left.\left(\mathrm{f}_{\mathrm{i}}\right)\right)\left(\mathrm{f}_{\mathrm{j}}:-\right.$-adormecido- $\left.\left.\left.\left(\mathrm{f}_{\mathrm{j}}\right)\right)\right]\left(\mathrm{x}_{\mathrm{i}}\right)_{\mathrm{U}}\left(\mathrm{e}_{\mathrm{i}}\right)\right)$

(84c) NM: (Ap $\mathrm{i}$ : $\left[\left(\mathrm{Aw}_{\mathrm{i}}-\mathrm{sentado}-\left(\mathrm{Aw}_{\mathrm{i}}\right)\right)\left(\mathrm{Gw}_{\mathrm{i}}\right.\right.$ : $\left./ \mathrm{mas} /\left(\mathrm{Gw}_{\mathrm{i}}\right)\right)\left(\mathrm{Aw}_{\mathrm{j}}\right.$-adormecido- $\left.\left.\left(\mathrm{Aw}_{\mathrm{j}}\right)\right)\right]$ $\left(\mathrm{Ap} \mathrm{p}_{\mathrm{i}}\right)$

(85) -> meus pais não, mas meus avós. (BR80:ArteUrbana)

(85a) NI: (AI: (CI: [(RI: -pais-(RI)) (RJ : -avós- (RJ))CONTR] (CI)) (AI))

(85b) NR: $\quad\left(\mathrm{p}_{\mathrm{i}}\right.$ : $\left(\mathrm{ep}_{\mathrm{i}}\right.$ : $\left(\mathrm{e}_{\mathrm{i}}:\left(\right.\right.$ neg $\mathrm{x}_{\mathrm{i}}-$ meus pais- $\left.\left(\mathrm{x}_{\mathrm{i}}\right)\right)\left(\mathrm{x}_{\mathrm{j}}:-\right.$ meus avós- $\left.\left.\left.\left.\left(\mathrm{x}_{\mathrm{j}}\right)\right)\left(\mathrm{e}_{\mathrm{i}}\right)\right)\left(e \mathrm{p}_{\mathrm{i}}\right)\right)\left(\mathrm{p}_{\mathrm{i}}\right)\right)$

(85c) NM: (Cli: $\left[\left(\mathrm{Np}_{\mathrm{i}}\right.\right.$ : -meus pais- $\left.\left(\mathrm{Np}_{\mathrm{i}}\right)\right)\left(\mathrm{Gw}_{\mathrm{i}}\right.$ : (não) $\left.\left(\mathrm{Gw}_{\mathrm{i}}\right)\right)\left(\mathrm{Gw}_{\mathrm{j}}\right.$ : (mas) $\left.\left(\mathrm{Gw}_{\mathrm{j}}\right)\right)\left(\mathrm{Np}_{\mathrm{j}}-\right.$ meus avós- $\left.\left.\left.\left(\mathrm{Np}_{\mathrm{j}}\right)\right)\right]\left(\mathrm{Cl}_{\mathrm{i}}\right)\right)$

Vimos nesta seção que mas, quando combina Atos Discursivos, indica a Função Retórica de Concessão no sentido de haver uma copresença de concessividade no Nível Interpessoal e adição no Nível Representacional. No entanto, quando combina Subatos, mas indica a Função Pragmática Contraste, confrontando duas informações no sentido da conjunção alemã sondern ou da conjunção espanhola sino e da italiana ma.

Em resumo, a combinação de unidades linguísticas por meio de mas indica duas estratégias interpessoais, a depender da camada envolvida. Ao combinar dois Atos Discursivos, estabelece uma relação de dependência entre eles, em que o primeiro (subsidiário) dá suporte para o segundo (nuclear). Nesse caso, estamos tratando de uma estratégia de natureza proposital, usada para persuadir o Ouvinte a aceitar os propósitos do Falante. Essa estratégia caracteriza a função retórica Concessão, que, quando marcada por mas, indica concessividade no Nível Interpessoal e adição no Nível Representacional, oriunda diacronicamente da natureza adverbial de mas. 
A combinação de unidades do Ato Discursivo, ou seja, de Subatos, consiste também em uma estratégia interpessoal, em que o Falante leva em conta as expectativas que tem do estado mental do Ouvinte, para determinar as partes de uma unidade linguística que serão apresentadas como particularmente salientes. Nesse caso, estamos tratando da função pragmática Contraste, em que o uso de mas assinala o desejo do Falante de realçar diferenças particulares entre dois Subatos, necessariamente explícitos na expressão linguística. Em outras palavras, o português dispõe de duas estratégias para indicar a função pragmática Contraste: estando as informações contrastadas explícitas, o expediente utilizado é mas; por outro lado, quando apenas uma informação está explícita e a outra contextualmente disponível, lança mão de partículas, como só, apenas, principalmente, também, entre outros. Sendo assim, o português distingue claramente o Foco Paralelo e o Foco Contrapressuposicional (Dik 1997a: 331-332).

\section{Considerações finais}

Voltando às questões colocadas na Introdução, podemos concluir que a natureza interpessoal da coordenação, proposta por Hengeveld/Mackenzie (2008), se confirma, no sentido em que todos os exemplos que analisamos envolvem o Nível Interpessoal. No entanto, argumentamos que a coordenação como fenômeno morfossintático resulta da dupla ação dos níveis Interpessoal e Representacional. As relações aditiva e alternativa (expressas por $e$ e $o u$ ) resultam não só de paralelismo no Nível Interpessoal, mas também de operações no Nível Representacional, operações que lançam mão de noções encontradas na lógica. A relação adversativa expressa por mas, porém, revela-se como idêntica à aditiva no Nível Representacional, diferenciando-se somente no Nível Interpessoal, onde requer a presença da função retórica Concessão atribuída a um Ato Discursivo dependente. Esta análise resume-se no Quadro 1.

\begin{tabular}{|l|l|l|l|l|}
\hline \multicolumn{2}{|l|}{ Tipo de coordenação } & Aditiva & Alternativa & Adversativa \\
\hline \multirow{3}{*}{ Níveis } & Interpessoal & equipolência & equipolência & dependência \\
\cline { 2 - 5 } & Representacional & adição $(\Lambda)$ & alternância $(\mathrm{V})$ & adição $(\Lambda)$ \\
\cline { 2 - 5 } & Morfossintático & $e$ & ou & mas \\
\hline
\end{tabular}

Quadro 1: Resumo da nossa proposta

Propusemos ainda uma análise de orações subordinadas coordenadas baseada no princípio da ocupação múltipla do mesmo nicho de uma camada do Nível Representacional, por exemplo em (51) o preenchimento do nicho do Undergoer/Inativo por dois Conteúdos Proposicionais.

Encaramos a combinação de constituintes suboracionais de forma análoga no que toca às relações aditiva e alternativa, mas analisamos os exemplos suboracionais de $\mathrm{X}$ mas $\mathrm{Y}$ ao fazermos apelo a uma das três funções retóricas reconhecidas na GDF, a saber o Contraste. Neste caso, trata-se da apresentação de dois subatos válidos, contrastados pelo falante, que desempenham papéis paralelos no discurso.

A nossa última questão de pesquisa foi descrever que tipo de processo morfossintático esses fenômenos engendram. No Nível Representacional propusemos operadores de adição $(\Lambda)$ e de 
alternância (V), que se atribuem a todos os elementos apresentados como adicionais ou alternativos ao primeiro elemento:

(86a) $\left[\left(v_{1}\right)\left(\wedge v_{2}\right) \ldots\left(\wedge v_{n}\right)\right]$ Adição

(86b) $\left[\left(\mathrm{v}_{1}\right)\left(\mathrm{V}_{\mathrm{V}}\right) \ldots\left(\mathrm{V}_{\mathrm{n}}\right)\right]$ Alternância

No Nível Morfossintático, porém, é normal expressar a respetiva relação só no último constituinte da Listagem: A, B, C e/ou D.

Esperamos ter dado mais alguns passos, além da coletânea Construções coordenadas nas variedades portuguesas: uma perspectiva discursivo-funcional, organizada por Pezatti/Camacho/Hattnher (2021), rumo a uma análise mais abrangente da coordenação na GDF, quadro teórico que até à data prestou pouca atenção a esse fenômeno. É nossa esperança que a utilização de representações explícitas dos vários níveis de análise ajude os pesquisadores futuros a aprofundar o trabalho aqui apresentado.

\section{Referências}

Anscombre, Jean Claude/Ducrot, Oswald (1977): "Deux Mais en français". Língua 43: 23-40. Barreto, Therezinha Maria Mello (1999): Gramaticalização das conjunções na história do Português. Tese de Doutoramento. Salvador, Universidade Federal da Bahia.

Bolinger, Dwight (1961): “Contrastive accent and contrastive stress”. Language 37: 83-96.

Camacho, Roberto Gomes (1999): “Estruturas coordenadas aditivas”. In: Neves, Maria Helena de Moura (org.): Gramática do português falado. 2a $2^{\text {a }}$ ed. São Paulo, Humanitas/FFLCH/USP; Campinas, Editora da Unicamp 7: 351-405.

Camacho, Roberto Gomes et al. (2021): "Coordenação oracional aditiva". In: Pezatti, Erotilde/Camacho, Roberto/Hattnher, Marize (orgs.): Construções coordenadas nas variedades portuguesas: uma perspectiva discursivo-funcional. $1^{\text {a }}$. ed. Campinas-SP, Mercado de Letras: 69-118.

Câmara Jr., Joaquim Mattoso (1976/1991): Problemas de lingüística descritiva. 14ª ed. Petrópolis, Vozes.

Chafe, Wallace (1976): "Givenness, contrastiveness, definiteness, subjects and topics”. In: Li, Charles (ed.): Subject and topic. Nova Iorque, Academic Press: 26-55.

Comparini, Ana Maria/Guiraldelli, Lisângela/Silva, Vítor H. S. da (2021): "Coordenação não oracional aditiva". In: Pezatti, Erotilde/Camacho, Roberto/Hattnher, Marize (orgs.): Construções coordenadas nas variedades portuguesas: uma perspectiva discursivofuncional. $1^{\text {a }}$ ed., Campinas-SP, Mercado de Letras: 197-224.

Dik, Simon: (1968/1972): Coordination: Its Implications for the Theory of General Linguistics. Amsterdã: North-Holland.

Dik, Simon (1997a): “The Theory of Functional Grammar." Part I: The structure of the clause Berlim/Nova Iorque: de Gruyter.

Dik, Simon: (1997b): "The Theory of Functional Grammar." Part II: Complex and derived constructions. Berlim/Nova Iorque: de Gruyter.

Garcia, Talita Storti et al. (2021): "Coordenação oracional adversativa". In: Pezatti, Erotilde/Camacho, Roberto/Hattnher, Marize (orgs.): Construções coordenadas nas variedades portuguesas: uma perspectiva discursivo-funcional. $1^{\text {a }}$. ed. Campinas-SP, Mercado de Letras: 155-193. 
Gasparini-Bastos, Sandra/Parra-Araújo, Beatriz/Souza-Martins, Nathalia (2021): "Coordenação oracional alternativa". In: Pezatti, Erotilde/Camacho, Roberto/Hattnher, Marize (orgs.): Construções coordenadas nas variedades portuguesas: uma perspectiva discursivofuncional. $1^{\text {a }}$ ed. Campinas-SP, Mercado de Letras: 119-154.

Grice, Paul H. (1975): "Logic and conversation". In: Cole, Peter/Morgan, Jerry (eds.): Syntax and semantics. Vol 3. Nova Iorque, Academic Press: 41-58.

Hattnher, Marize Dall'Aglio/Nagamura, George/Nuss, Virginia (2021): “Coordenação não oracional alternativa". In: Pezatti, Erotilde/Camacho, Roberto/Hattnher, Marize (orgs.): Construções coordenadas nas variedades portuguesas: uma perspectiva discursivofuncional. $1^{\text {a }}$ ed. Campinas-SP, Mercado de Letras: 225-258.

Hengeveld, Kees/Mackenzie, J. Lachlan (2008): Functional Discourse Grammar: A Typologically-Based Theory of Language Structure. Oxford: Oxford University Press.

Hengeveld, Kees/Mackenzie, J. Lachlan (2012): “Gramática Discursivo-Funcional”. In: Souza, Edson Rosa (org.): Funcionalismo linguístico: novas tendências teóricas. São Paulo, Contexto 1: 43-86.

Hengeveld, Kees/Mackenzie, J. Lachlan (2018): "Negation in Functional Discourse Grammar". In: Keizer, Evelien/Olbertz, Hella (eds): Advances in Functional Discourse Grammar. Amsterdã: Benjamins.

Ilari, Rodolfo/Neves, Maria Helena de Moura (orgs.) (2008): “Gramática do português falado culto" Vol. 2: Classes de palavras e processos de construção. Campinas-SP: Editora da Universidade Estadual de Campinas.

Keizer, Evelien (2015): A Functional Discourse Grammar for English. Oxford: Oxford University Press.

Longhin, Sanderléia/Pezatti, Erotilde/Novaes-Marques, Norma (2019): “A Coordenação". In: Castilho, Ataliba (org.): História do Português Brasileiro: mudança sintática das construções: perspectiva funcionalista. São Paulo, Contexto: 26-93.

Mackenzie, J. Lachlan (2018): “Testing for constituents: A response from Functional Discourse Grammar". Language Under Discussion. Vol. 5 Issue 1 (April): 45-51. journals.helsinki.fi/lud/article/view/225.

Maurer Jr, Theodoro Henrique (1959): Gramática do latim vulgar. Rio de Janeiro: Livraria Acadêmica.

Moutaouakil, Ahmed (1988): Pragmatic functions in functional grammar of Arabic [trans. from the French by John Lachlan Mackenzie]. Dordrecht: Foris.

Neves, Maria Helena de Moura (2000): Gramática de usos do português. São Paulo: Editora Unesp.

Pezatti, Erotilde (1999): "Estruturas coordenadas alternativas". In: Neves, Maria Helena de Moura (ed.). Gramática do português falado. 2.ed. São Paulo, Humanitas/Campinas-SP, Editora da Unicamp 7: 407-441.

Pezatti, Erotilde (2012): "Clivagem e construções similares: contraste, foco e ênfase". Lingüística 28: 73-98.

Pezatti, Erotilde (2021): “A Gramática Discursivo-Funcional e a Coordenação”. In: Pezatti, Erotilde/Camacho, Roberto/Hattnher, Marize (orgs.): Construções coordenadas nas variedades portuguesas: uma abordagem discursivo-funcional. Campinas-SP, Mercado de Letras: 17-66. 
Pezatti, Erotilde/Longhin, Sanderléia (2008): "As construções coordenadas". In: Ilari, Rodolfo/Neves, Maria Helena de Moura (orgs.): Gramática do português culto falado no Brasil: classes de palavras e processos de construção. Campinas-SP, Editora da Unicamp: 865-932.

Pezatti, Erotilde/Camacho, Roberto/Hattnher, Marize (orgs.) (2021): Construções coordenadas nas variedades portuguesas: uma abordagem discursivo-funcional. Campinas-SP: Mercado de Letras.

Pezatti, Erotilde/Galvão Passetti, Gabriel (2021): “Coordenação não oracional adversativa". In: Pezatti, Erotilde/Camacho, Roberto/Hattnher, Marize (orgs.): Construções coordenadas nas variedades portuguesas: uma perspectiva discursivo-funcional. $1^{\mathrm{a}}$ ed. Campinas-SP, Mercado de Letras: 259-300.

Sweetser, Eve (1990): From Etymology to Pragmatics: Metaphorical and Cultural Aspects of Semantic Structure. Nova Iorque: Cambridge University Press.

Taglicht, John (1984): Message and Emphasis: On Focus and Scope in English. Londres: Longman.

Zhang, Niina Ning (2009): Coordination in Syntax. Cambridge: Cambridge University Press. 